\title{
Calculation of a Tunnel Cross Section Subjected to Fire with a New Advanced Transient Concrete Model for Reinforced Structures
}

\author{
U. Schneider, M. Schneider, J.-M. Franssen
}

The paper presents the structural application of a new thermal induced strain model for concrete - the TIS-Model. An advanced transient concrete model (ATCM) is applied with the material model of the TIS-Model. The non-linear model comprises thermal strain, elastic strain, plastic strain and transient temperature strains, and load history modelling of restraint concrete structures subjected to fire.

The calculations by finite element analysis (FEA) were done using the SAFIR structural code. The FEA software was basically new with respect to the material modelling derived to use the new TIS-Model (as a transient model considers thermal induced strain). The equations of the ATCM consider a lot of capabilities, especially for considering irreversible effects of temperature on some material properties. By considering the load history during heating up, increasing load bearing capacity may be obtained due to higher stiffness of the concrete. With this model, it is possible to apply the thermal-physical behaviour of material laws for calculation of structures under extreme temperature conditions.

A tunnel cross section designed and built by the cut and cover method is calculated with a tunnel fire curve. The results are compared with the results of a calculation with the model of the Eurocode 2 (EC2-Model). The effect of load history in highly loaded structures under fire load will be investigated.

A comparison of this model with the ordinary calculation system of Eurocode 2 (EC2) shows that a better evaluation of the safety level was achieved with the new model. This opens a space for optimizing concrete structure design with transient temperature conditions up to $1000^{\circ} \mathrm{C}$.

Keywords: Material model, transient thermal strain, thermal creep, tunnel, concrete, fire.

\section{Introduction}

Calculations to predict the deformation rate and load bearing capacity of concrete structures at high temperatures are often based on material models according to the model of Eurocode 2 (EC2-Model). In Europe, most calculations of structures are based on this model. The model is very usable and provides a high level of safety for members under bending and standard fire test conditions. It has not been tested for natural fire conditions which include decreasing temperature conditions.

The load bearing capacity of concrete structures can be optimized with models representing transient material behaviour. Models which are approximated by transient data are more realistic. The following investigation describes the potential when using a new transient concrete model. This model considers thermal induced strain with external load or internal restraint load during heating up. For this model, a realisation of all components of concrete strain is needed. The concrete behaviour is influenced by transient temperature and load history.

A material model for calculation of siliceous concrete is given in [1]. This new model is based on the Thermal-Induced-Strain-Model (TIS-Model) and is called the Advanced Transient Concrete Model (ATCM). Transient conditions during the whole calculation routine are taken into account. The transient load and the real temperature development are considered. Generally, an ATCM can be used for all types of concrete; only some parameters have to be changed. This examination is based on ordinary concrete with siliceous aggregates.
The general calculation method is divided into thermal and mechanical analyses, which are normally nonlinear. Using this model, Finite Element Analysis (FEA) is applied to the calculation [2]. In order to determine the time / temperature curves within the concrete, the thermal equation is solved with the inclusion of heat transfer through thermal analysis [3]. Mass transports can also be included, because during fire exposure many phase transitions of the cement stone matrix and aggregate appear $[4,5]$. These thermally conditioned physico-chemical variables can have influences on the mechanical model $[6,7,8]$. The mechanical analysis is based on these results. There are numerous models available for determining the behavior of ordinary concrete at high temperatures $[9,10,11]$. In regard to this, there is also high dependency on the type of concrete, used as studies for ultra-high performance concrete have shown (UHPC) [12, 13].

In a first step, the behaviour of small cylinders with siliceous concrete is calculated. The results are obtained using an ATCM, which determines all local stresses and mechanical strains considering the whole cross section. These results are based on measured results according to [14]. In addition, a calculation of restraint stresses is given. The FEA considers different material behaviour which allows all results obtained with the new model to be compared with the results of calculations obtained with the EC2-Model, which is widely used in Europe.

The two concrete models, the EC2-Model and ATCM based on material properties according to TIS-Model (see equation (1), show a very different behaviour for deformation and restraint stresses during calculation. The influence of the load during heating is essential. 
The calculations with simple structures show a good approximation between calculation results and measured data [15].

The good adaptation of the new ATCM to measured data gives hope for a good adaptation in the calculation of complex structures. A cut and cover rectangular-shape reinforced concrete tunnel is calculated with the new model in the following sections.

\section{Generals and calculation results with concrete models}

\subsection{General TIS-Model}

It is generally agreed that the total strain $\varepsilon_{\text {tot }}$ comprises the following parts:

$$
\varepsilon_{\mathrm{tot}}=\varepsilon_{\mathrm{el}}+\varepsilon_{\mathrm{pl}}+\varepsilon_{\mathrm{tr}}+\varepsilon_{\mathrm{th}},
$$

where $\varepsilon_{\text {tot }}$ total strain, $\varepsilon_{\text {el }}$ elastic strain, $\varepsilon_{\text {pl }}$ plastic strain, $\varepsilon_{\text {tr }}$ total transient creep strain, $\varepsilon_{\text {th }}$ thermal dilatation.

It is therefore convenient to write for the pure mechanical strain:

$$
\varepsilon_{\mathrm{m}}=\varepsilon_{\mathrm{el}}+\varepsilon_{\mathrm{pl}}+\varepsilon_{\mathrm{tr}}=\varepsilon_{\mathrm{tot}}-\varepsilon_{\mathrm{th}} .
$$

During an isothermal creep test the following types of deformation occur, see Fig. 1.

According to [17], in this case the term is called "load inducted thermal strain". It consists of transient creep (transitional thermal creep and drying creep), basic creep and elastic strains. The shrinkage during the first heating is accounted for by the observed thermal strain (load $0 \%$ ).

Fig. 2 shows a general evolution of the total strain for specimens under different constant loads during heating up, based on the TIS-Model. The high influence of load during transient heating is to be seen. The elastic strain is very small

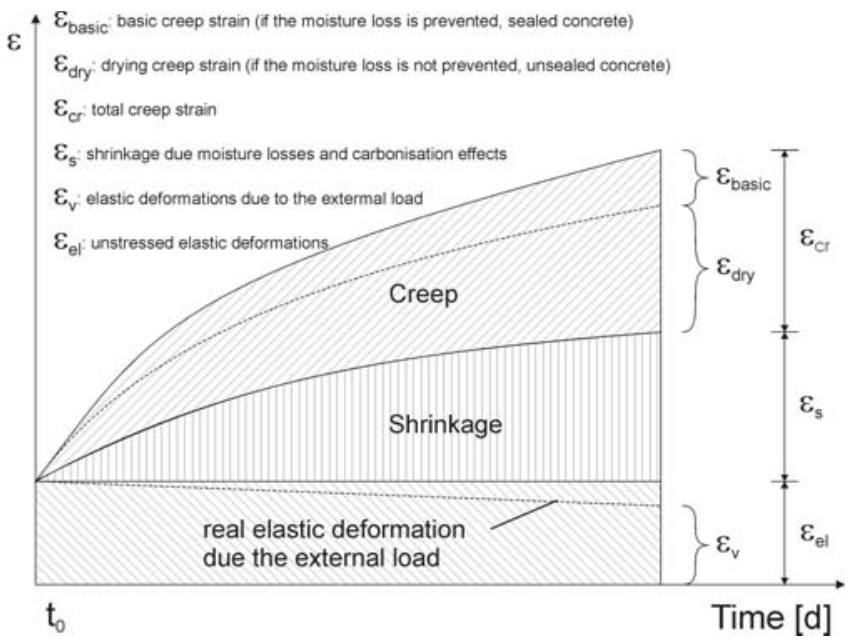

Fig. 1: Deformations of concrete at ambient temperatures subjected to a constant compressive load, according to [16]

at temperature $T=20{ }^{\circ} \mathrm{C}$ compared to the high deformation at high temperatures.

It is concluded that the irreversible character of the main material properties must be incorporated in a calculation model to ensure a realistic consideration of the behavior of concrete.

\subsection{Calculation of total strains with the ATCM and EC2 Method}

\subsubsection{Model parameters for calculation of total strains with the EC2 and ATCM Method}

The specimens are cylinders $80 \mathrm{~mm}$ in diameter and $300 \mathrm{~mm}$ in height. The heating rate is $2 \mathrm{~K} / \mathrm{min}$. The compressive strength at $20^{\circ} \mathrm{C}$ is $38 \mathrm{MPa}$. The moisture content is

\section{Total strain at high temperatures as function of load history}

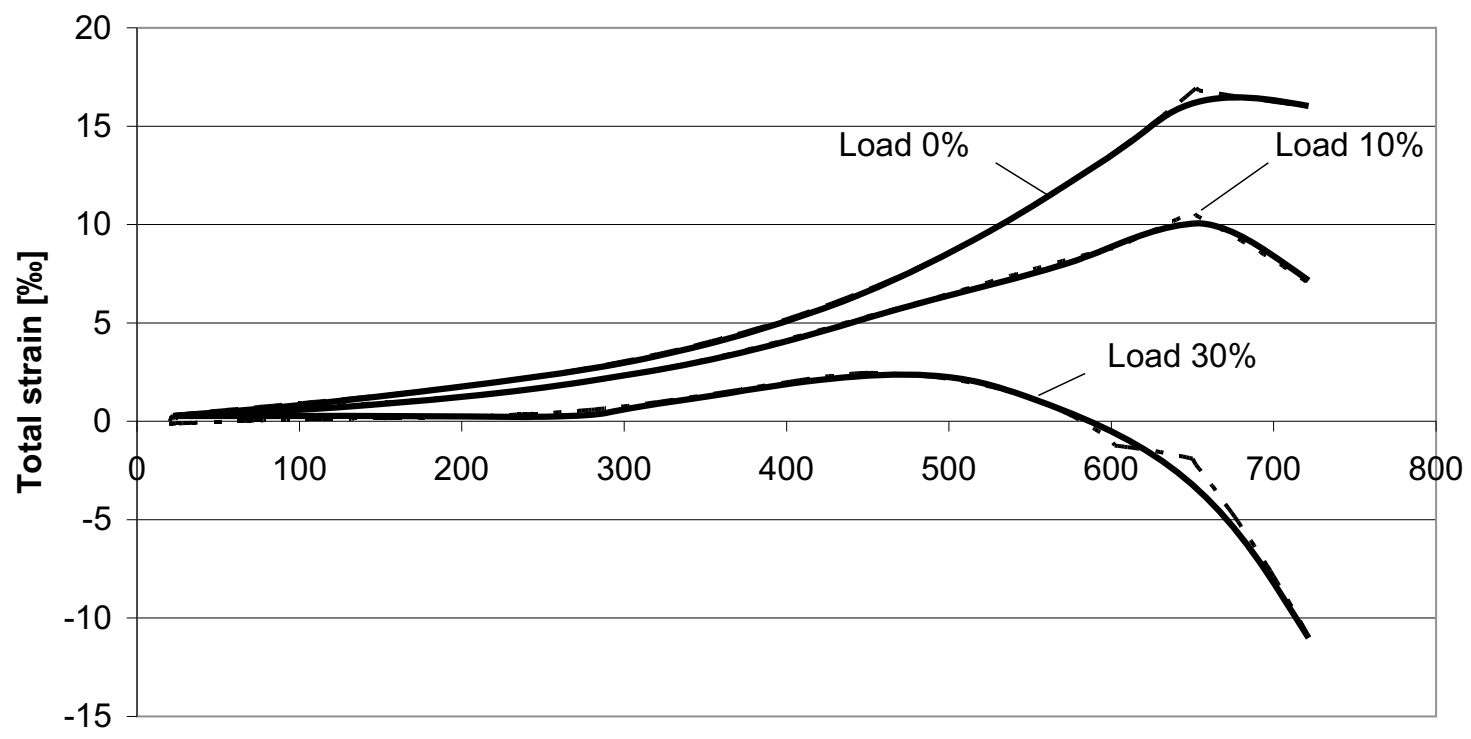

Temperature $\left[{ }^{\circ} \mathrm{C}\right]$

Fig. 2: Total strain at high temperatures as a function of load history 


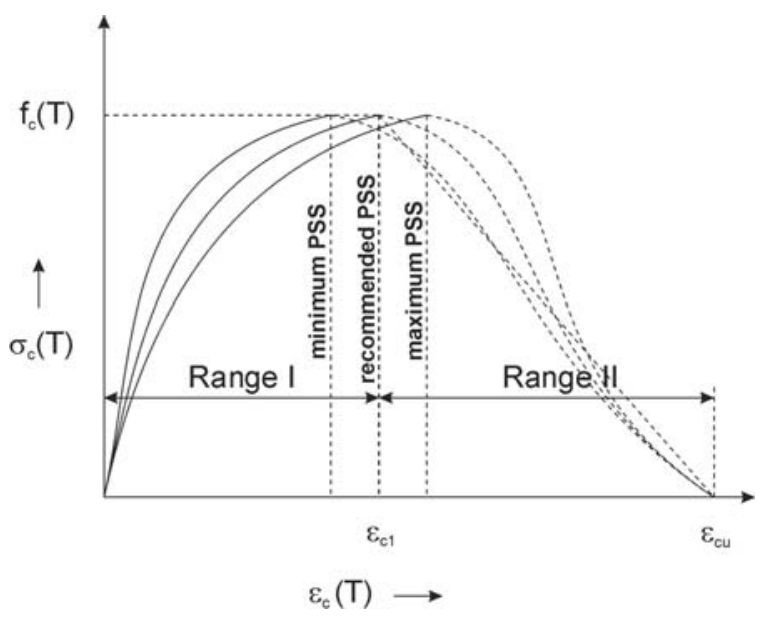

Fig. 3: Stress strain relationship subjected to fire, according to EC2 [18] $w=2 \%$. The results are obtained from heated specimens under different stress-time relationships [14].

In the advanced transient concrete model (ATCM), the TIS-Model is used. The FEA uses a model taken from Eurocode 2 with a stress-strain constitutive model with minimum, recommended and maximum values of the peak stress strain. The minimum value of the peak stress strain (PSS) is nevertheless not considered further, because the results are at a very negative side compared to the other models. Fig. 3 shows the different peak stress strain values.

The concrete behaviour shows a different Young's Modulus during heating: the higher the PSS, the smaller the Young's Modulus. The practical relationship according to the measured data is not shown in Eurocode 2. The stress-strain relationship in Eurocode 2 is also used for a normative temperature condition, according to ISO 824 (ISO fire curve).

Stress-Time-Relationship

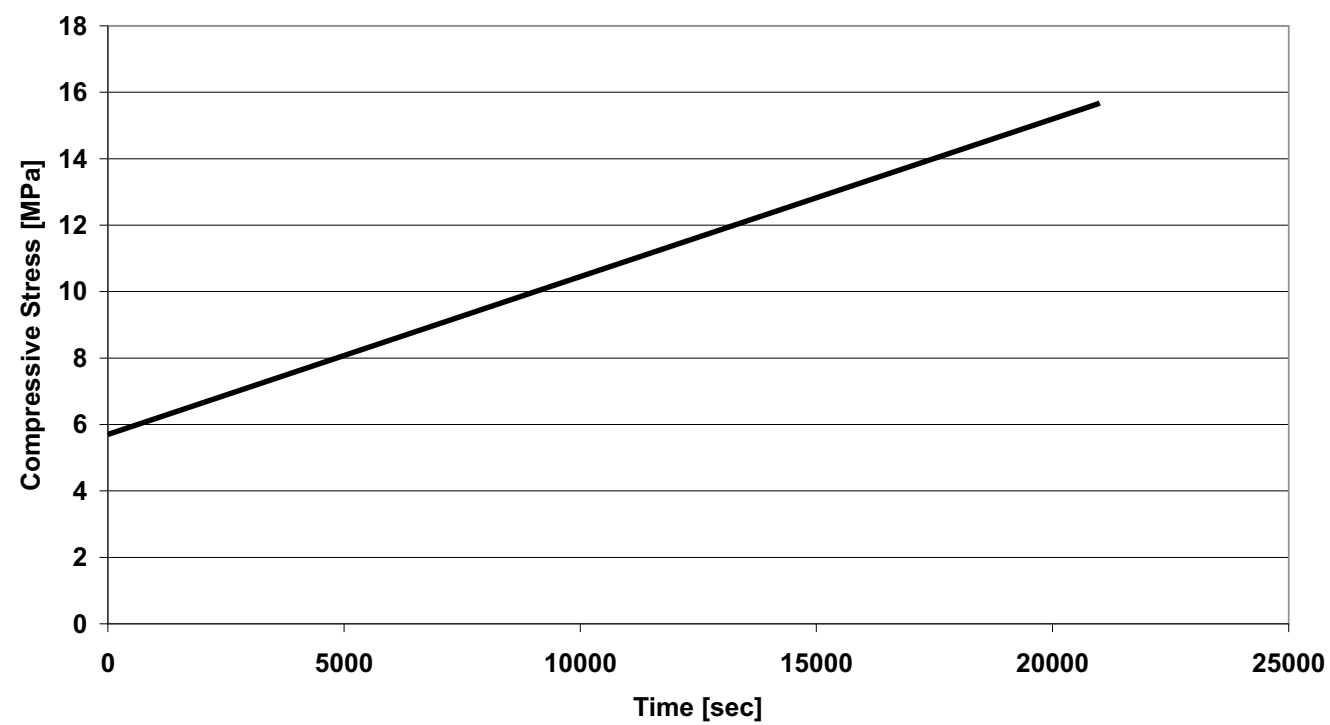

Fig. 4: Stress-Time Relationship with constantly increasing load

Comparison between measurements and calculated data with different concrete models

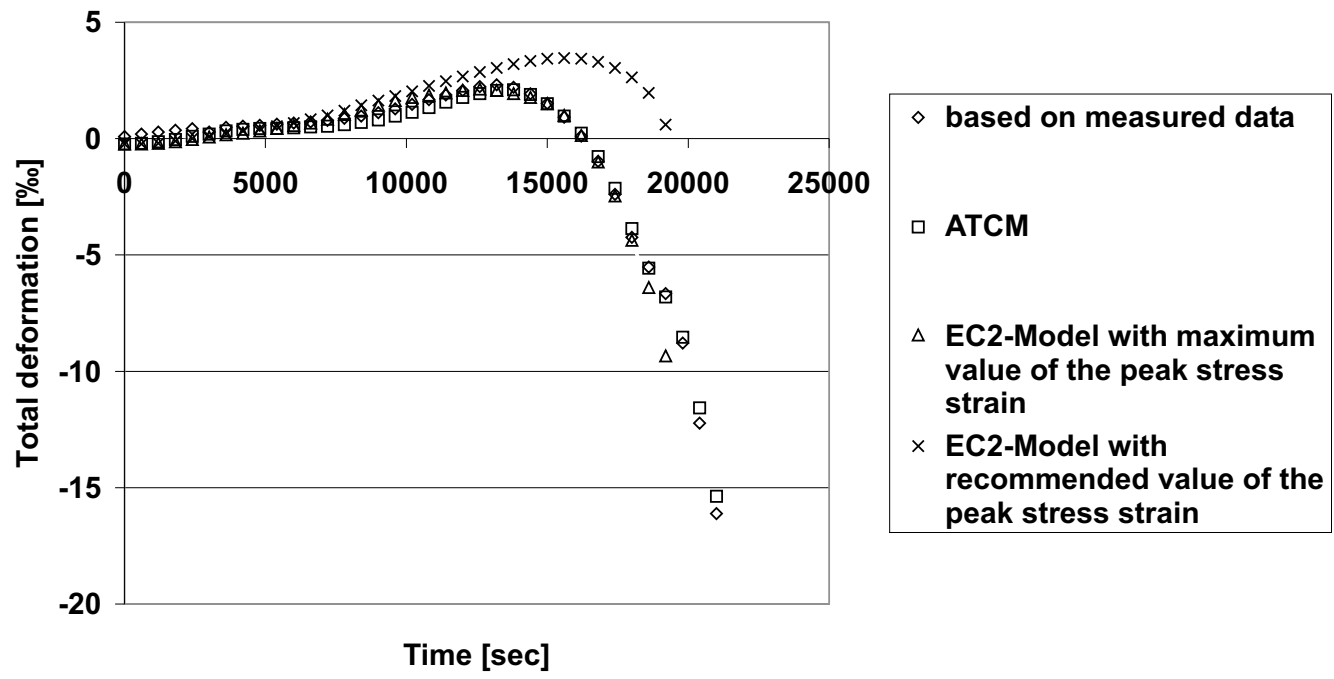

Fig. 5: Comparison of measured and calculated total strains under an applied load function according to Fig. 4 


\subsubsection{Results of measurements and calculations of total strains with an ATCM and EC2 Model}

The calculation is done with different load functions during heating. The ATCM method is also well approximated for the mechanical strain according to measured data according to [14]. Fig. 4 shows the load function as stress-time relationship of a constant increasing load. A comparison between the ATCM method and the EC2 calculation is shown in Fig. 5.

The ATCM with the TIS-Model are very well approximated with the measured based data. The result of the calculation with the EC2 Model with the maximum PSS value is generally as good as the value approximated by ATCM. The calculation with the recommended value of PSS is totally different above $3.5 \mathrm{~h}$.

Fig. 6 shows the evolution of stress as a function of time that has been considered, with a linear increase until 15000 seconds and a linear decrease thereafter. Fig. 7 shows the results of the comparison.

The EC2 Model with the maximum value of PSS and the FEA with the ATCM approximated very well, as did the result of the calculation with EC2-Model considering the maximum value of PSS. The calculation with the EC2 Model with the recommended value of PSS generally has more deformation than the other calculations.

Stress-Time-Relationship

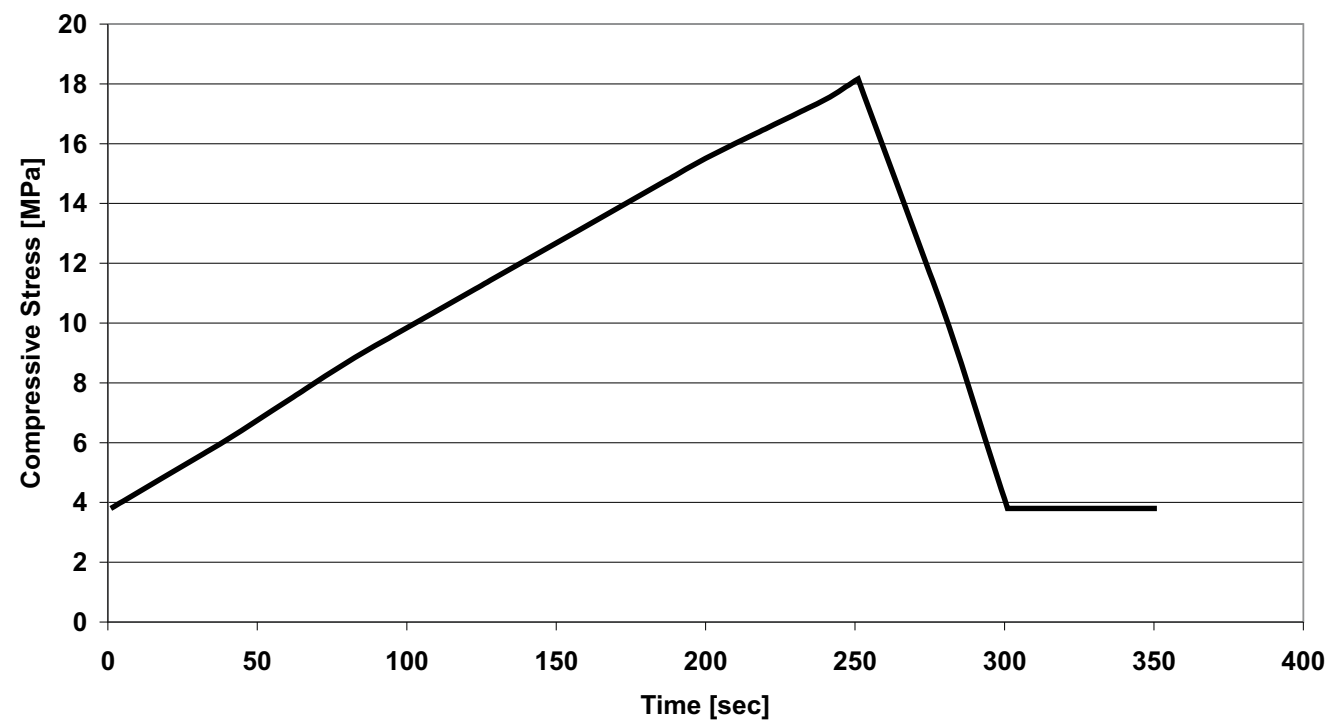

Fig. 6: Stress-Time Relationship with continuously increasing load with continuous decreasing above 15000 seconds

Comparison between measurements and calculated data with different concrete models

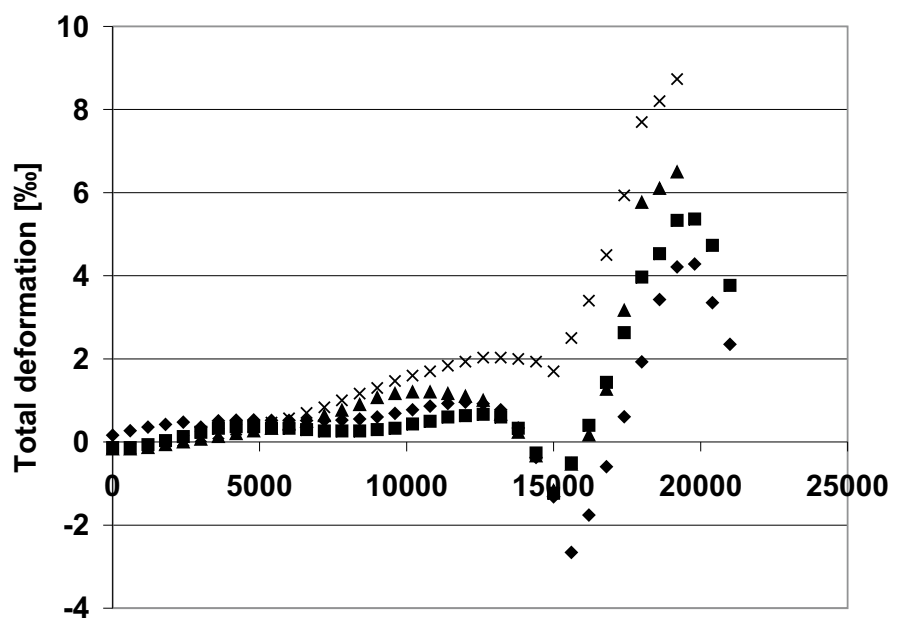

- based on measured data

- ATCM

$\triangle$ EC2-Model with maximum value of the peak stress strain

$\times$ EC2-Model with

recommended value of the peak stress strain

Time [sec]

Fig. 7: Comparison of measured and calculated total strains under an applied load function according to Fig. 6 


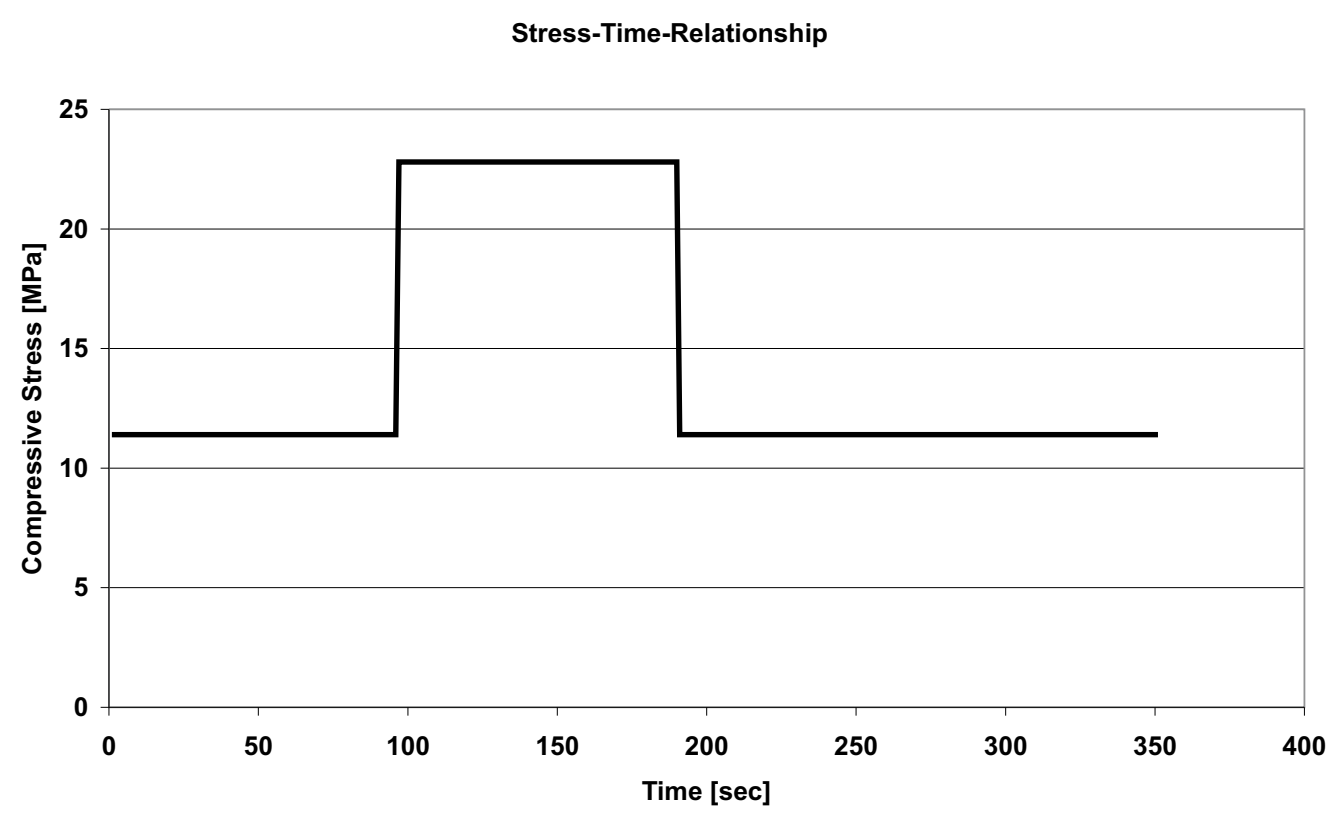

Fig. 8: Stress-Time Relationship with a sudden increase of the load and a sudden decrease till the origin

Comparison between measurements and calculated data with different concrete models

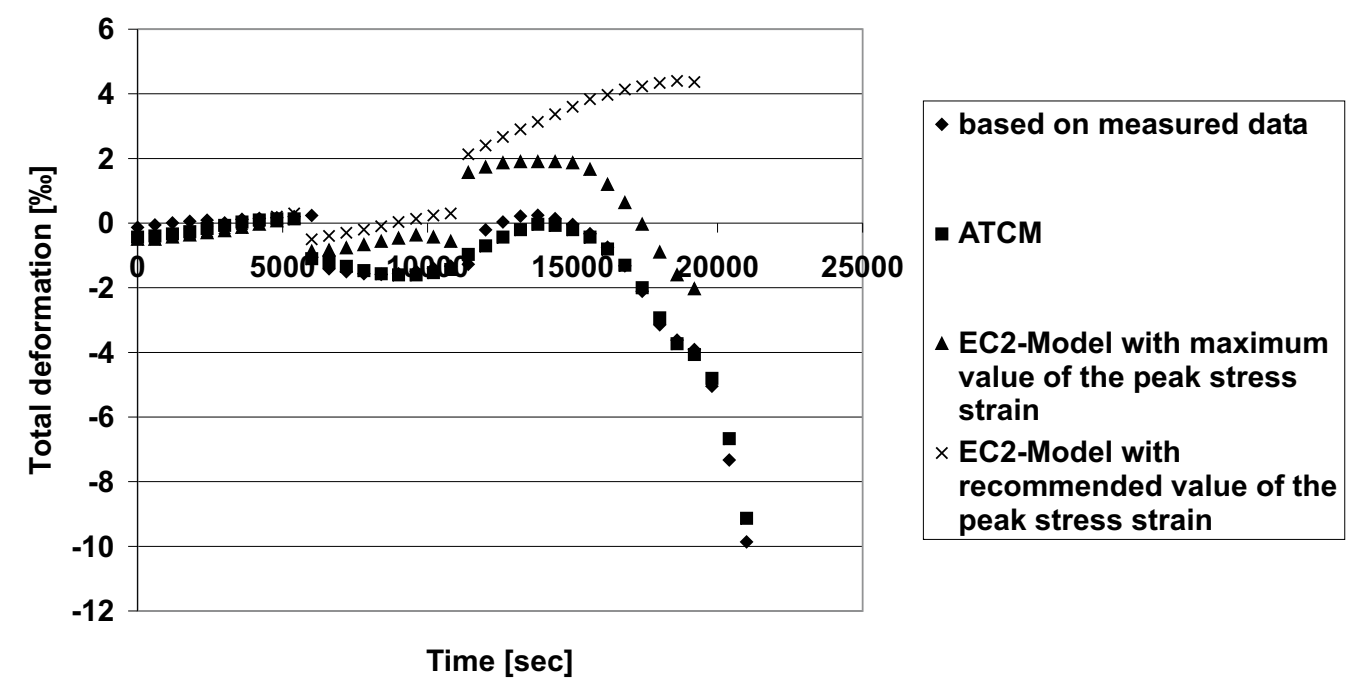

Fig. 9: Comparison of measured and calculated total strains under an applied load function according to Fig. 8

The load function as a stress-time relationship with stepwise application of the load and stepwise unloading is given in Fig. 8. A comparison between the different models is shown in Fig. 9.

The approximation between the two compared calculation methods with the ATCM is comparatively good. However, a much higher difference between the total strains calculated with the ATCM and the EC2 Model with the maximum PSS value is observed. The result of the calculation with the EC2 Model with the recommended value of PSS is significantly different from the calculations with the ATCM and from the test results.
Fig. 10 shows the load function as a stress-time relationship with 3 increasing load steps and 3 decreasing load steps. Fig. 11 shows a comparison between the different calculation models.

The differences generally increase between the calculations with the EC2 Model and ATCM. The calculations with the ATCM are a good approximation of the test results. The EC2 models, whatever value of PSS is chosen, do not allow deformations to be calculated under a load function with a complex stress-time-relationship. For this calculation, ATCM must be used. 
Stress-Time-Relationship

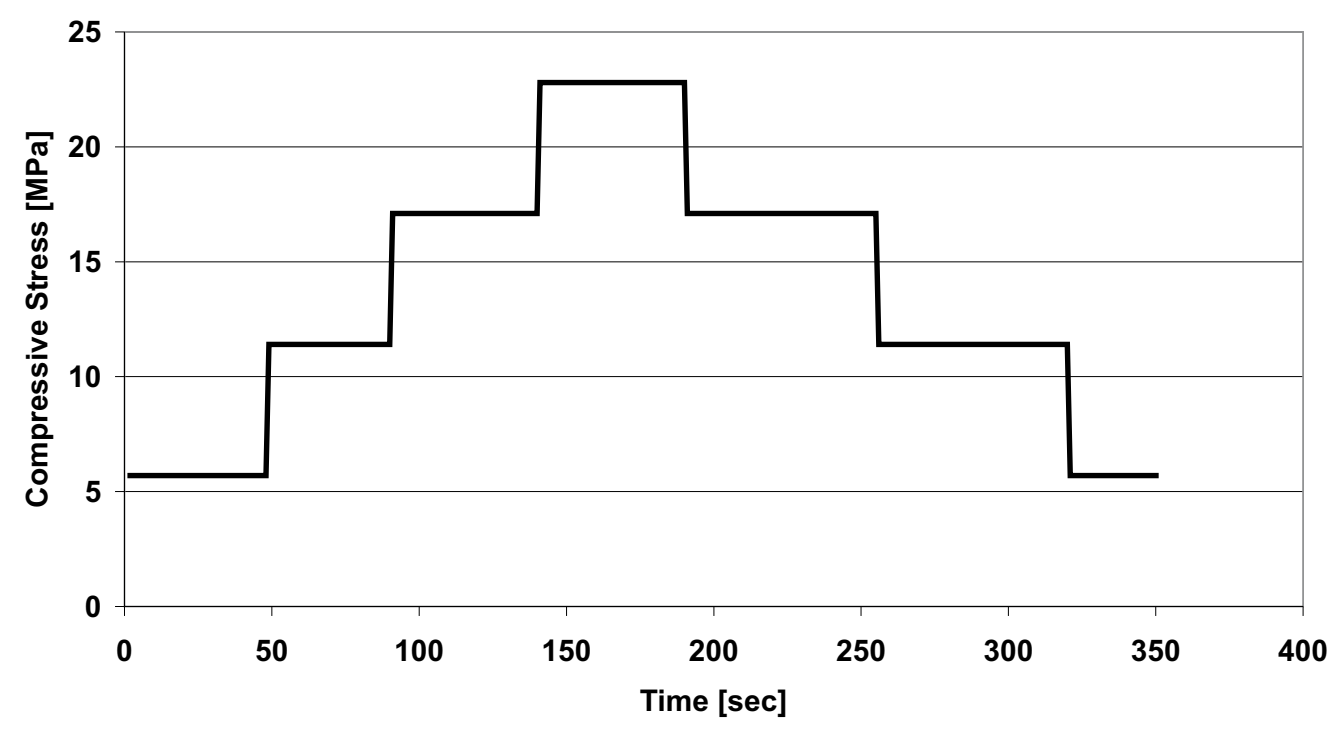

Fig. 10: Stress-Time Relationship with 3 sudden increases in load and 3 sudden decreases till the origin

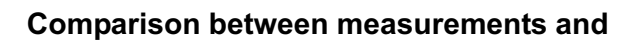
calculated data with different concrete models

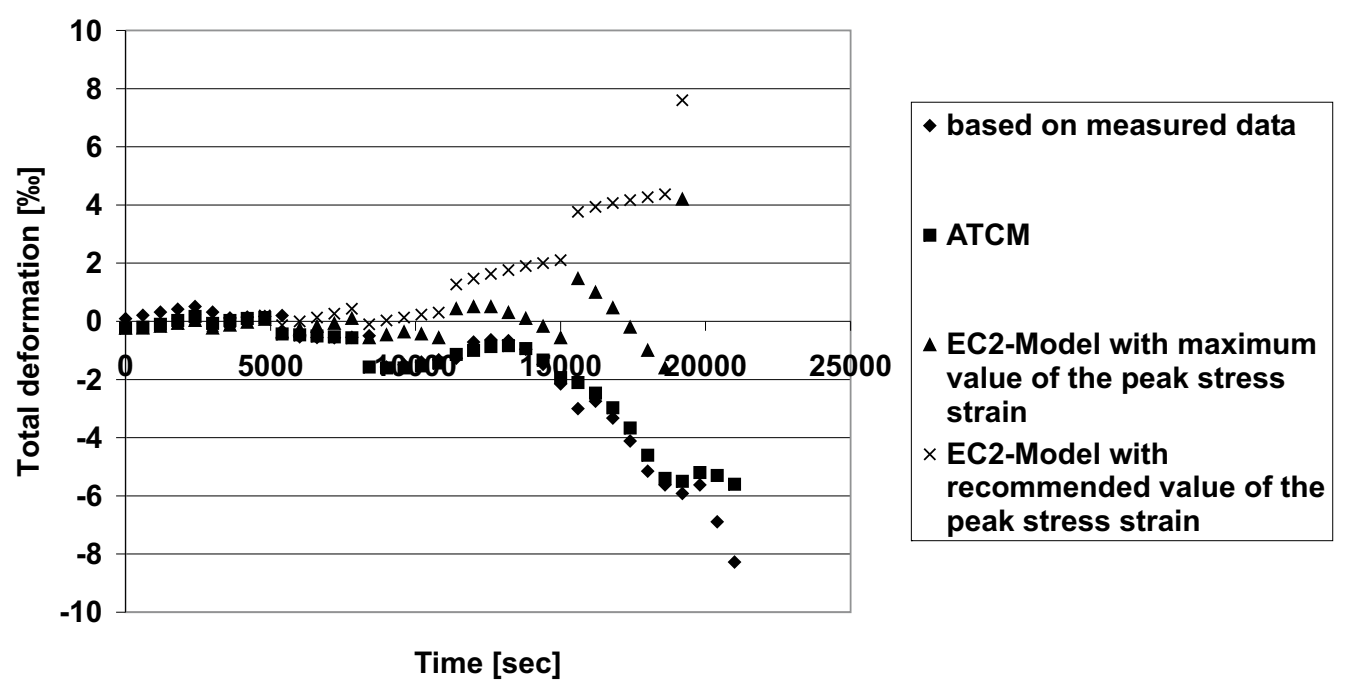

Fig. 11: Comparison of measured and calculated total strains under an applied load function according to Fig. 10

\subsection{Calculation of restraint axial force of a specimen under restraint condition}

\subsubsection{Model parameters calculation of restraint axial force under restraint condition}

The specimens are calculated with the ATCM and the EC2 Model under restraint conditions and with a heating rate of $2 \mathrm{~K} / \mathrm{min}$. The restraint deformation applied at the beginning of the calculation is kept constant during heating up.

The specimens are cylinders $80 \mathrm{~mm}$ in diameter and $300 \mathrm{~mm}$ in height. The cube compressive strength of the siliceous concrete at $20^{\circ} \mathrm{C}$ is $20 \mathrm{MPa}$ and it has a moisture content of $w=2 \%$.

\subsubsection{Calculation results of restraint axial forces for a heated specimen which is fully restrained}

The following figures compare the results of the calculation with the ATCM with measured data taken from [14]. Fig. 12 shows the restraint axial forces during heating with a load factor of 0.3 . The measured data is based on different storage conditions during curing.

The curve of the ATCM is below the data of $105^{\circ} \mathrm{C}$ dried concrete specimen till $300{ }^{\circ} \mathrm{C}$ and near the standard cured concrete $(w=2-4 \%)$. Above a temperature of $300{ }^{\circ} \mathrm{C}$, the curve of the ATCM is close to the curve of the water stored specimen. The curve of ATCM lies in the confidence interval of all curves. Fig. 13 shows the ratio of restraint axial force di- 
Axial force during heating with load factor 0.3

compared to measured results

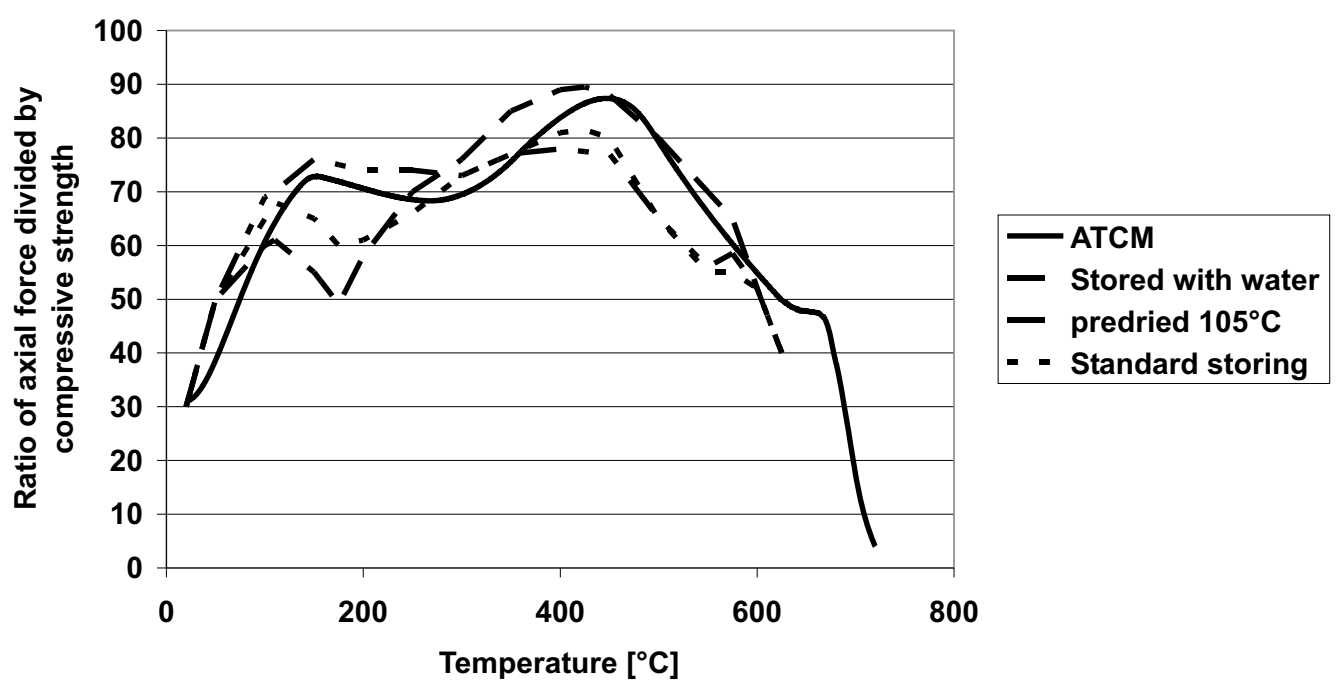

Fig. 12: Restraint axial force during heating with a load factor 0.3 compared to measured results

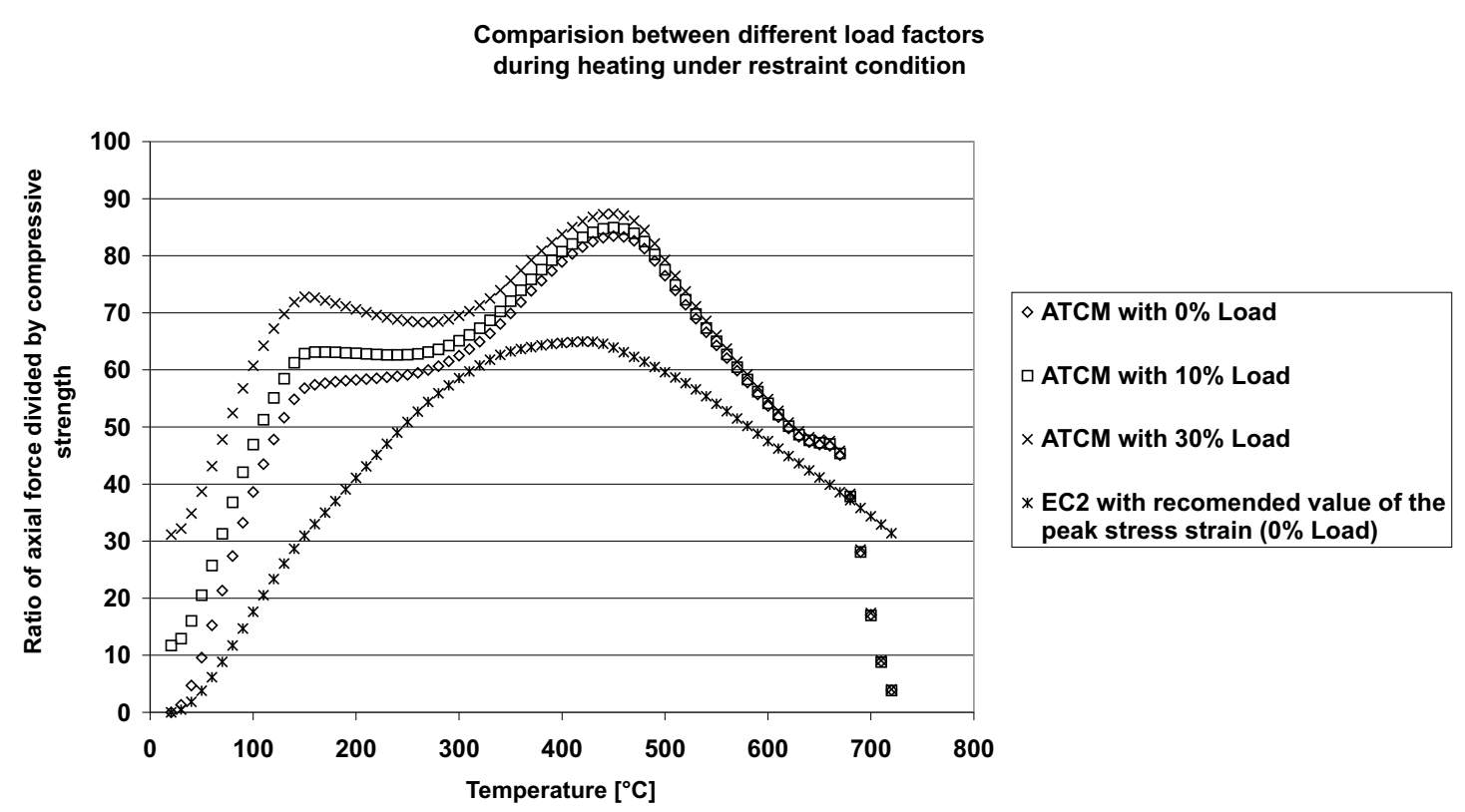

Fig. 13: Comparison of restraint forces for different load factors

vided by compressive strength. The figure compares the restraint axial forces under different load conditions. The EC2 Model is a stress-strain constitutive model without considering the load factor, i.e. it does not yield a good simulation result for restraint.

At a temperature less than $420^{\circ} \mathrm{C}$ the different load conditions indicate different restraint axial forces. Above $420{ }^{\circ} \mathrm{C}$ the curves are nearly identical. The higher the load level, the higher are the restraint axial forces.

The lines of the calculation with the EC2 Model do not give a good approximation to the results of the ATCM. From the experimental result of Fig. 12 we come to the conclusion that EC2 Model simulations do not give a good approxima- tion of the measured values. The restraint axial forces are significantly lower than the measured data.

Since the axial stress has a significant effect on the fire resistance of building elements according to [19], a realistic simulation is important for loaded structures.

\subsection{Calculation of a tunnel cross section}

\subsubsection{Model of the calculation of a tunnel cross section}

In general, calculation methods have two separate arithmetic steps: a thermal analysis and a mechanical analysis. For further information, please see the references [17, 20, 21]. The calculation model was divided into the following parts of the structure, see Fig. 14. 
- ground plate BEAM $01=$ symmetric axis of the cross section at node 1

BEAM 12 = mid-point between BEAM 01 and BEAM 20 at node 20

BEAM $20=$ corner between ground plate and wall at node 41

- wall

BEAM 23 = corner between wall and ground plate at node 41

BEAM 36 = point of maximum bending moment at node 75

BEAM $49=$ corner between ceiling and wall at node 97

- ceiling

BEAM $49=$ corner between wall and ceiling at node 97

BEAM 60 = mid-point between BEAM 49 and BEAM 71 at node 120

BEAM $71=$ symmetric axis of the cross section at node 143

In the following example, a single-bay frame is calculated. It is a model of a tunnel taken from a research project, shown in Fig. 14 [22].

The simulation calculates a tunnel cross section with an exposition of a HCI curve [23].
Derived from the Hydrocarbon curve, the maximum temperature of the HCI curve is $1300{ }^{\circ} \mathrm{C}$ instead of the $1100{ }^{\circ} \mathrm{C}$ standard HC curve. Fig. 15 shown the time-temperature relationship. Such fires may occur in accidents involving tank trucks [7, 24].

The arithmetic model is based on a section 1 meter in width [25]. General calculations utilize the semi-probabilistic concept of Eurocode 1 [17, 26].

The bedding is considered with the help of a spring component under every beam element of the ground plate [27]. The material used here is ordinary siliceous concrete C25/30 and steel BSt500.

The heating is calculated for transient heating. Before the structure is subjected to fire, the basic combination must be used to determine the amount of reinforcement that is to be used for comparison purposes during the fire exposure. It is assumed that no spalling occurs during the fire.

\subsubsection{Results of the calculation of a tunnel cross section}

Figs. 16 to 17 show the results of the deformation with the EC2 Model with the maximum PSS value, and with the ATCM.

The various displacements demonstrate how the whole structure responds during heating. The stiffness of the system changes as a function of time [28, 29].

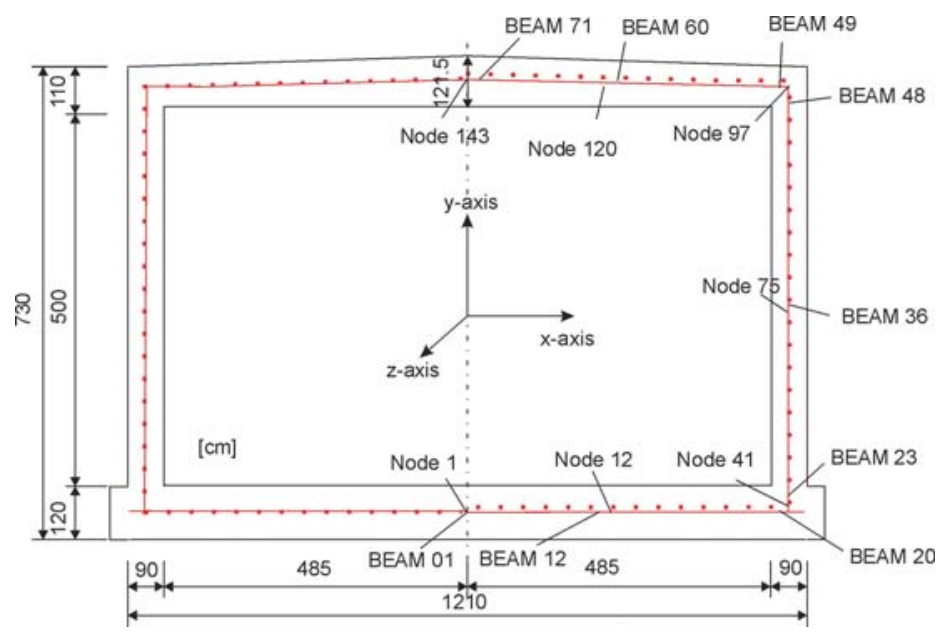

Fig. 14: Principle sketch of the tunnel; according to [22]

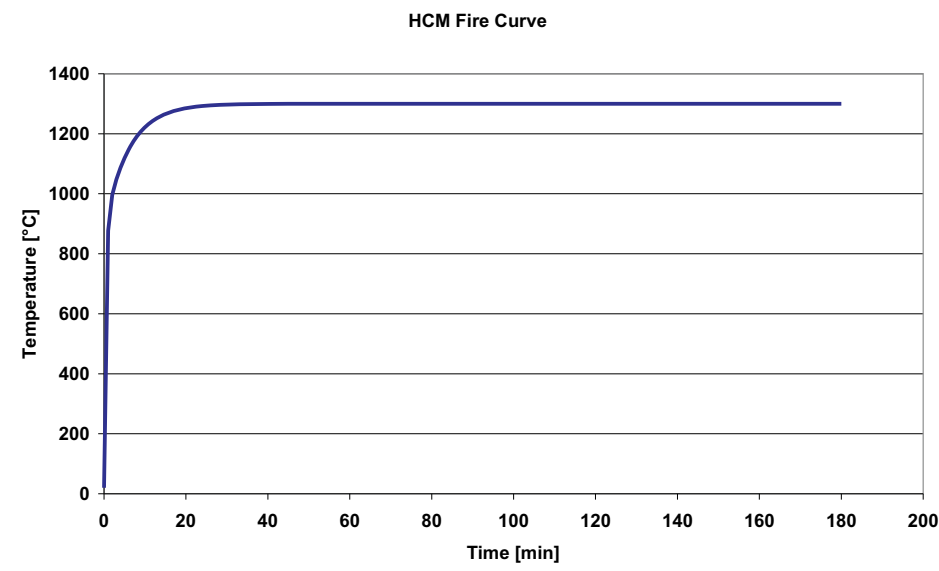

Fig. 15: Hydro Carbon Increased fire curve according to [7] 

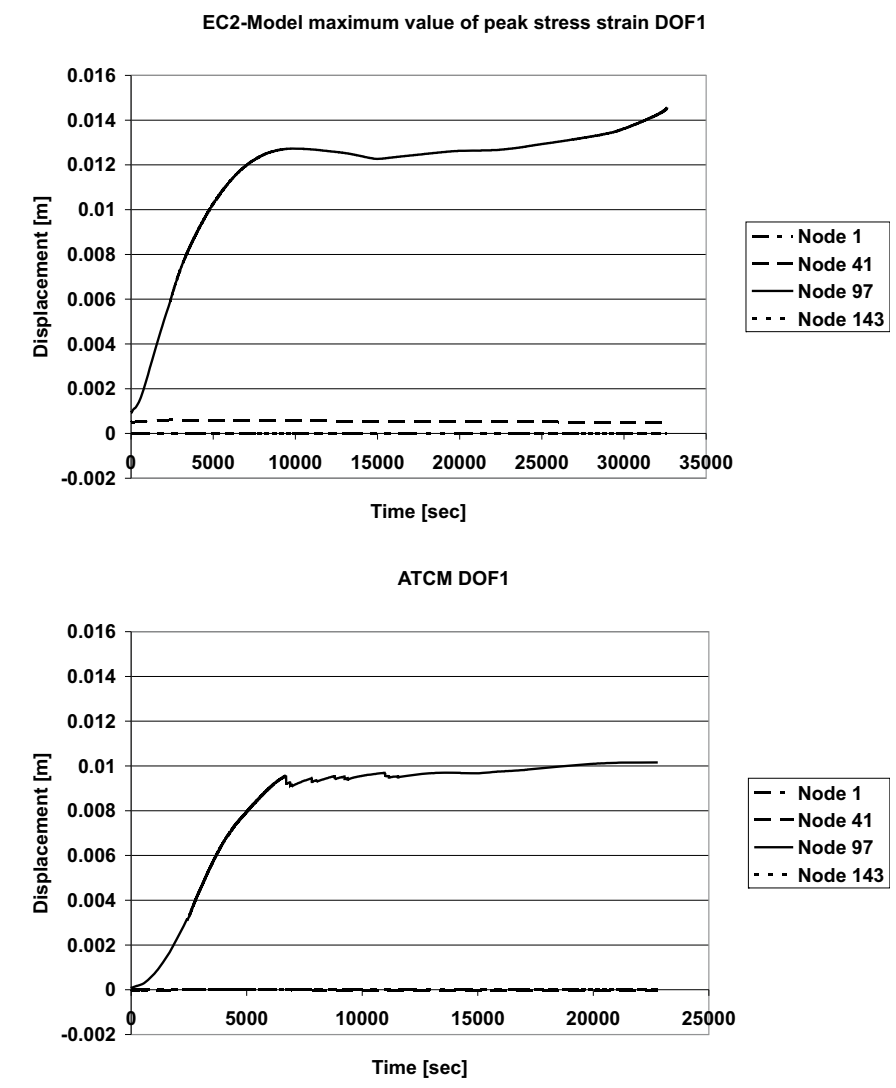

Fig. 16: Displacement in the $x$-axis in various nodes

Most of the deformations show a lower deformation with ATCM. Only in node 1 is the deformation in y-axis slightly
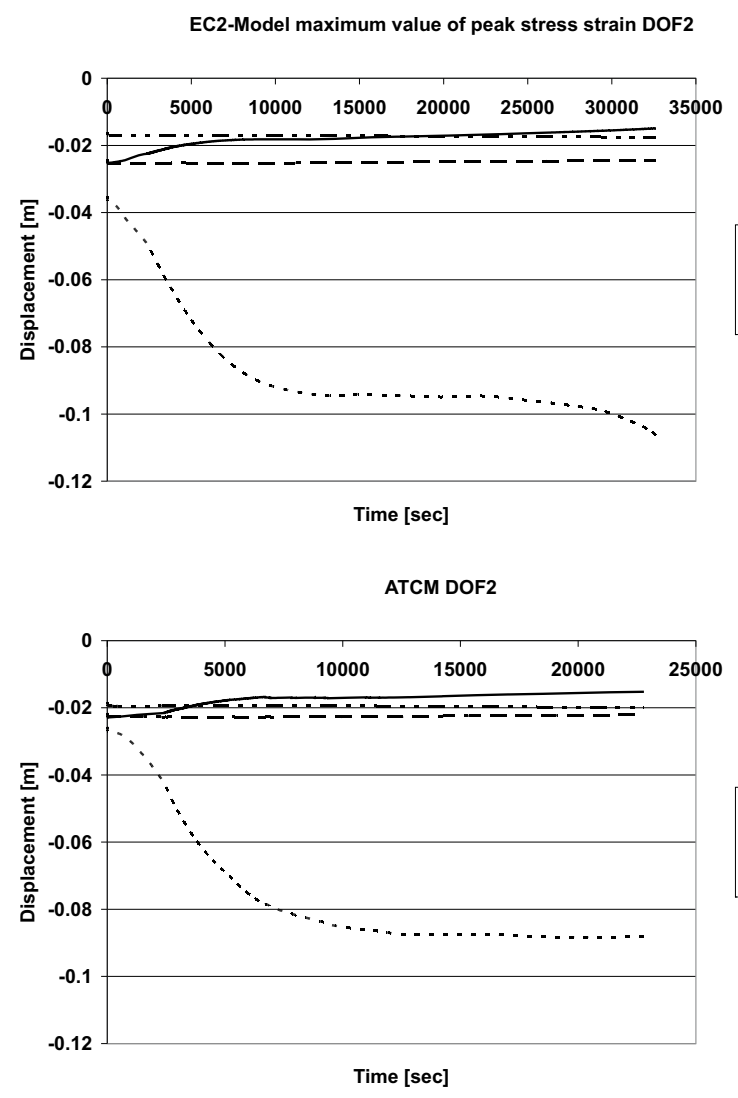

Fig. 17: Displacement in the $y$-axis in various nodes larger with ATCM than with the EC2 Model. These results show the effect of the higher load utilisation of the new model. Without considering the load history, the influence of the load under temperature exposure is not sufficiently reflected in the calculation of the deformation of the structure. The next figures show the mechanical properties of the strucure with respect to the axial forces and the bending moments.

Figures 18 to 23 show a comparison between the mechanical results.

The axial forces of the ground plate, the wall and the ceiling are generally higher according to simulations with the EC2 Model compared to simulations with ATCM. Due to the lower deformation in ATCM, lower axial forces occur. An insignificant difference between the two models is seen in the calculation of the bending moment. Positive bending moments are lower with ATCM than with the EC2 Model. Negative bending moments are higher with ATCM than with the EC2-Model.

\section{Discussion of the results}

To calculate the load bearing capacity and the behaviour of structures subjected to fire, new material equations for the most important material properties of ordinary concrete have been developed $[1,15]$. This model was developed to supplement the existing concrete model of EC2 with respect to the transient thermal creep and the effect of the load history. With this new model we can consider the load history in all phases of thermal exposure. With this complex model, we can calculate the total strain, taking into account a wide range of variations of load history and temperatures. Different parts of deformations are approximated with discrete equations inter-
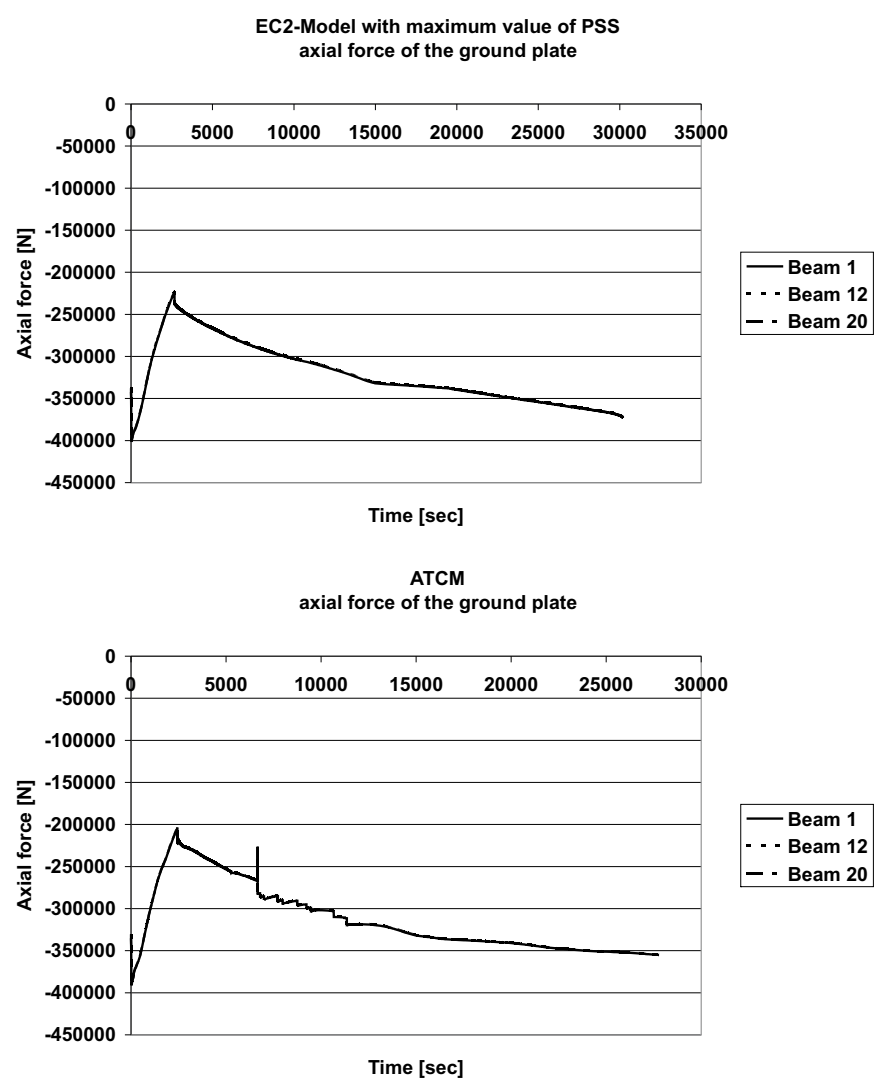

Fig. 18: Axial forces in various beams in the ground plate 
acting in the new concrete model. This technique can be used for realistic calculations of the behaviour of structures [30, 31, 32], especially in the case of restraint.

EC2-Model with maximum value of PSS axial force of the wall
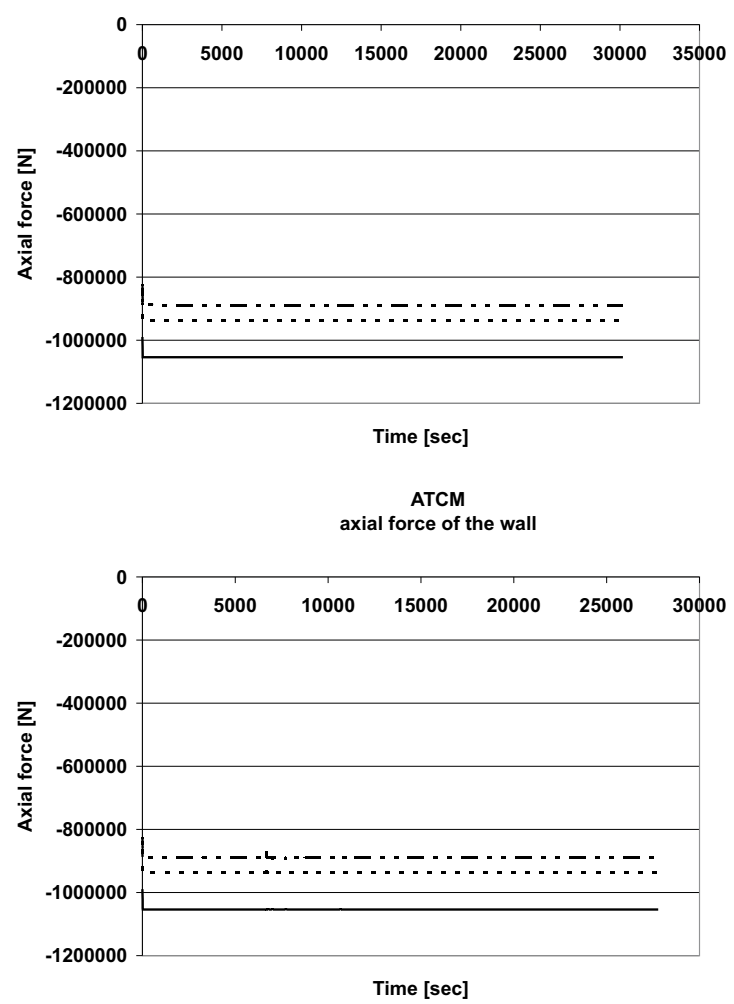

Fig. 19: Axial forces in various beams in the wall
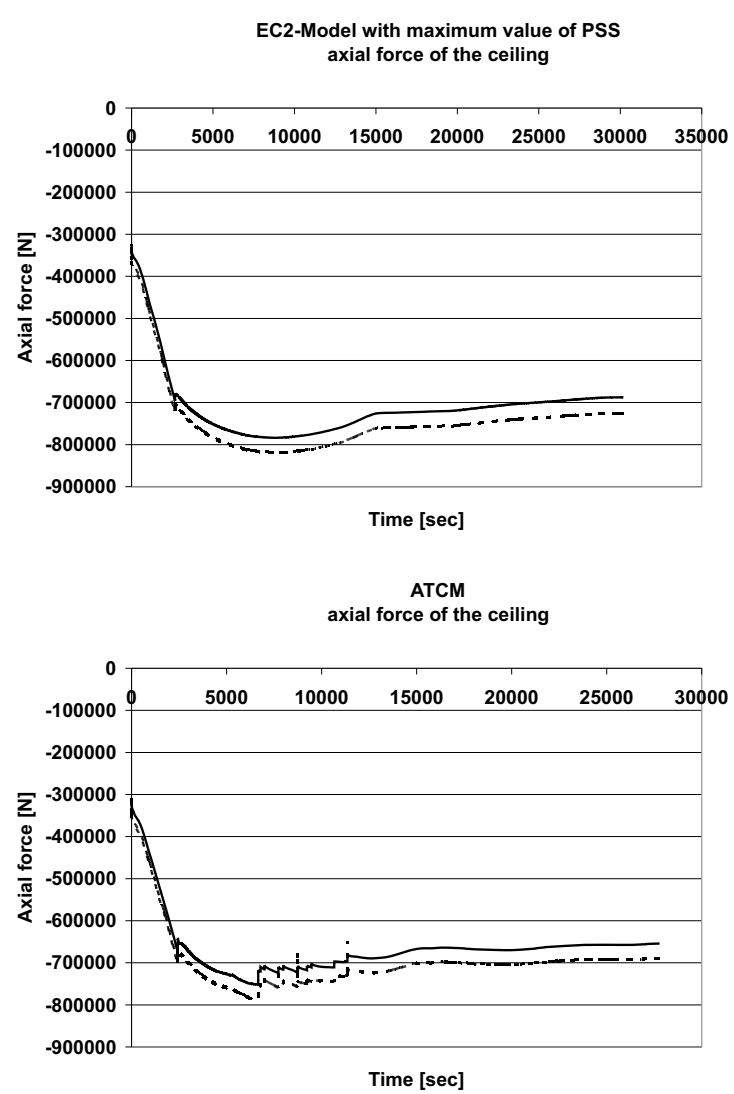

Fig. 20: Axial forces in various beams in the ceiling
By considering the load history during heating up, an increasing load bearing capacity due to higher stiffness of the concrete may be obtained in several cases. With this model,
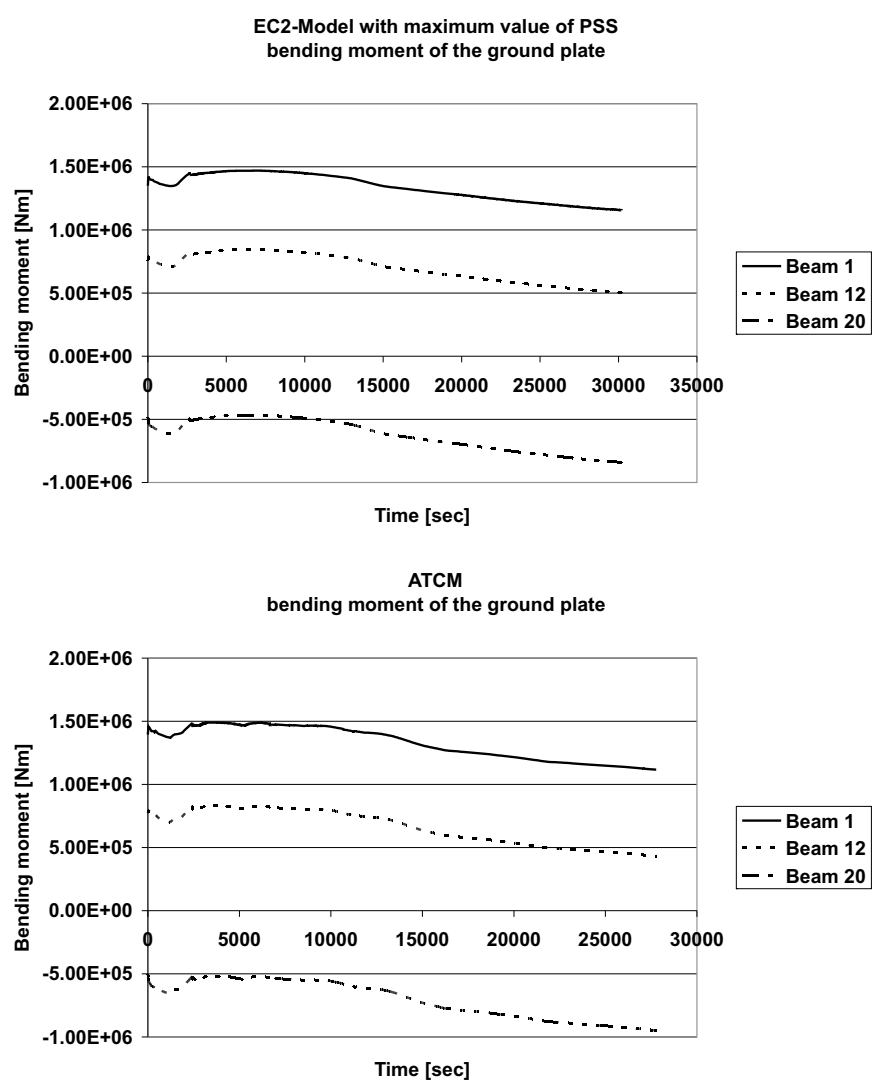

Fig. 21: Bending moments in various beams in the ground plate

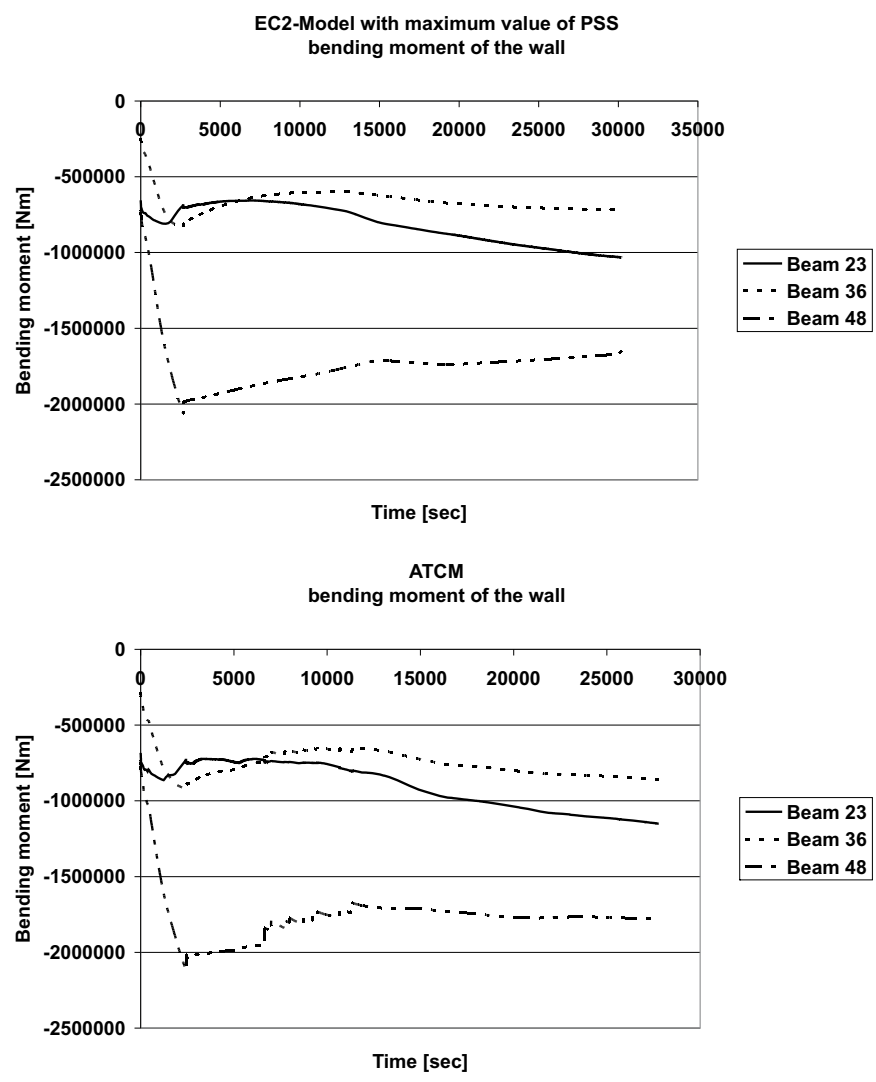

Fig. 22: Bending moments in various beams in the wall 

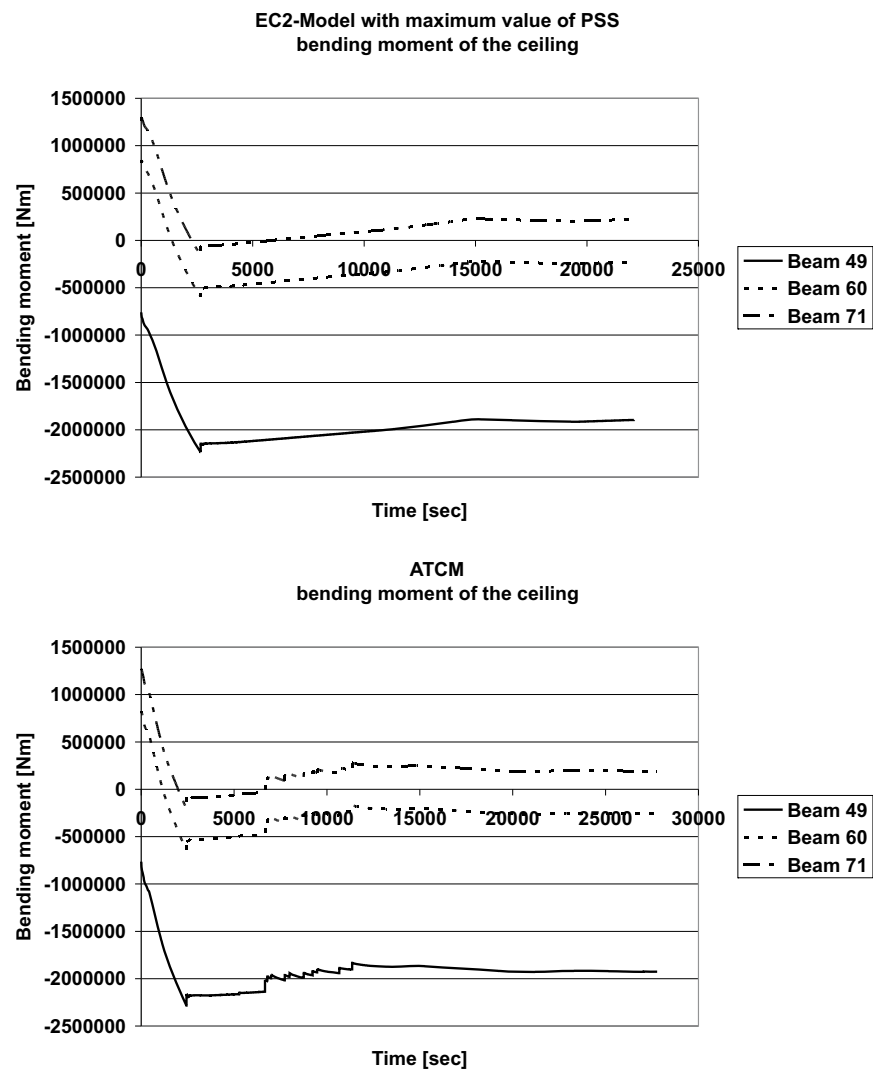

Fig. 23: Bending moments in various beams in the ceiling

we can consider the thermal-physical behaviour of material properties for the calculation of reinforced concrete structures. Application of this model, instead of the calculation system of EC2, will lead to a better evaluation of the safety level. This opens a space for optimizing reinforced concrete structures under temperature exposure.

A calculation of a tunnel cross section of a cut-and-cover single bay frame was performed and presented above. Lower deformations are calculated in all parts of the structures using the new Advanced Transient Concrete Model (ATCM). Due to this lower deformation, there is a lower axial force during heating.

The results of the calculation of the bending moments show a lower moment on the inside of the tunnel surface and a higher bending moment outside of the tunnel, if we compare the results of ATCM with those of the EC2 Model. The differences between the calculations are very small. Here we do not observe a significant difference in this structure when using the new model of concrete.

\section{Conclusion}

It has been shown that the recommended model of EC2 does not calculate realistic values of deformations of concrete structures under high temperature, when compared with the results of the Advanced Transient Concrete Model (ATCM), which is based on measured data. A maximum value of peak stress strain is necessary for a relatively realistic description of the behaviour of the structure. For calculation of tunnels with concrete with siliceous aggregates, the EC2 Model should be taken with the maximum value of the peak stress strain. For calculating a higher load bearing member, ATCM should be applied. Note that the full concrete behaviour is used in the structure only with the TIS-Model with the equations of ATCM.

Calculation with ATCM has a high potential for optimizing concrete structures, higher than the EC2 Model. The reliability of the load bearing capacity is higher with ATCM, because the deformations are lower than with the EC2 Model. The calculated axial forces with ATCM are with the EC2 Model are close to each other.

A potential is observed for more detailed calculations of complex structures. In the concept of structures it may be applied with lower safety factors, i.e. lower excess charges may be used in the design.

\section{References}

[1] Schneider, U., Schneider, M., Franssen, J.-M.: Consideration of Nonlinear Creep Strain of Siliceous Concrete on Calculation of Mechanical Strain under Transient Temperatures as a Function of Load History. Proceedings of the Fifth International Conference - Structures in Fire SIF 08, Singapore 2008, p. 463-476.

[2] Franssen J.-M.: SAFIR. A Thermal/Structural Program Modelling Structures under Fire. Engineering Journal, A.I.S.C., Vol 42 (2005), No. 3, p. 143-158.

[3] Pesaveto, F. et al.: Finite - Element Modelling of Concrete subjected to high Temperature. In: fib Task Group 4.3 - Fire Design of Concrete Structures: What now? What next? Milano 2004.

[4] Lang, E.: Feuerbeton, Schriftenreihe Spezialbetone Band 4, Verlag Bau + Technik, 2001.

[5] Wolf, G.: Untersuchung über das Temperaturverhalten eines Tunnelbetons mit spezieller Gesteinskörnung. Diplomarbeit, Technische Universität Wien, 2004.

[6] Florian, A.: Schädigung von Beton bei Tunnelbränden. Diplomarbeit, Universität Innsbruck, 2002.

[7] Schneider, U., Horvath, J.: Brandschutz - Praxis in Tunnelbauten, Bauwerk Verlag GmbH, Berlin, 2006.

[8] Debicki, G., Langhcha, A.: Mass Transport through Concrete Walls Subjected to High Temperature and Gas Pressure. In: fib Task Group 4.3 - Fire Design of Concrete Structures: What now? What next? Milano 2004.

[9] Schneider, U.: Verhalten von Betonen bei hohen Temperaturen; Deutscher Ausschuss für Stahlbeton. Berlin - München: Verlag Wilhelm Ernst \& Sohn, 1982.

[10] Horvath, J., Schneider, U.: Behaviour of Ordinary Concrete at High Temperatures. Institut für Baustofflehre, Bauphysik und Brandschutz, TU Wien 2003.

[11] Schneider, U., Morita, T., Franssen, J.-M.: A Concrete Model Considering the Load History Applied to Centrally Loaded Columns Under Fire Attack. In: Fire Safety Science - Proceedings of the fourth International Symposium, Ontario, 1994.

[12] Horvath, J.: Beiträge zum Brandverhalten von Hochleistungsbetonen, Technische Universität Wien 2003.

[13] Horvath, J., Schneider, U., Diedrichs, U.: Brandverhalten von Hochleistungsbetonen. Institut für Baustofflehre, Bauphysik und Brandschutz, TU Wien 2004. 
[14] Schneider, U.: Ein Beitrag zur Frage des Kriechens und der Relaxation von Beton unter hohen Temperaturen. (Habilitationsschrift) Institut für Baustoffe, Massivbau und Brandschutz, TU Braunschweig, Heft 42, Braunschweig, 1979.

[15] Schneider, U., Schneider, M., Franssen, J.-M.: Numerical Evaluation of Load Induced Thermal Strain in Restraint Structures Compared with an Experimental Study on Reinforced Concrete Columns. Proceedings of the $11^{\text {th }}$ International Conference and Exhibition, FIRE AND MATERIALS 2009, 26-28 January 2009, Fisherman's Wharf, San Francisco, USA.

[16] Khoury, G. A., Grainger, B. N., Sullivan, P. J. E.: Transient Thermal Strain of Concrete: Literature Review, Conditions with Specimens and Behaviour of Individual Constituents. Magazine of Concrete Research, Vol. 37 (1985), No. 132.

[17] Schneider, U., Lebeda, C., Franssen, J.-M.: Baulicher Brandschutz, Berlin: Bauwerk Verlag GmbH, 2008.

[18] Eurocode 2: Design of concrete structures - Part 1-2: General rules - Structural fire design. 2004.

[19] Dwaikat, M. B., Kodur, V. K. R.: Effect of Fire Scenario, Restraint Conditions, and Spalling on the Behaviour of RC Columns. Proceedings of the Fifth International Conference - Structures in Fire SIF 08, Singapore 2008, p. $463-476$.

[20] Franssen, J.-M.: Contributions à la Modélisation des Incendies dans les Bâtiments et leurs Effets sur les Structures, Université de Liège, Belgium 1998.

[21] Mason, J. E.: Heat Transfer Programs for the Design of Structures Exposed to Fire. University of Canterbury, Christchurch, 1999.

[22] Franssen, J.-M., Hanus, F., Dotreppe, J.-C.: Numerical Evaluation of the Fire Behaviour of a Concrete Tunnel Integrating the Effects of Spalling. In Proceedings fib Workshop - Coimbra, November 2007.

[23] ÖVBB-Sachstandsbericht: Brandeinwirkungen - Straße, Eisenbahn, U-Bahn. ÖVBB-Arbeitskreis AA1, Entwurf zum Grundstück, Verf.: Lemmerer, J. et al.: Wien, Januar 2005.

[24] SFPE: The SFPE Handbook of Fire Protection Engineering. $2^{\text {nd }}$ edition, Quincy, Ma, USA: SFPE, 1995.
[25] Wittke, W., Wittke-Gattermann, P.: Tunnelstatik. In: Beton Kalender 2005: Fertigteile-Tunnelbawwerke, Berlin: Verlag Ernst \& Sohn, 2005.

[26] Eurocode 1: Actions on structures. Part 1-1: General actions. Densities, self-weight, imposed loads for buildings. EN 1991-1-1:2002

[27] Beutinger, P., Sawade, G.: Standsicherheit - Vorhersagemöglichkeit der Bodentragfähigkeit aus geotechnischer Sicht, Tiefbau Tagung Magdeburg, 2004.

[28] Feron, C.: The Effect of the Restraint Conditions on the Fire Resistance of Tunnel Structures. In: fib Task Group 4.3 - Fire Design of Concrete Structures: What now? What next? Milano, 2004.

[29] VÖZFI: Abschlussbericht - Praxisverhalten von erhöht brandbeständigem Innenschalen-Beton, Wien, 2003.

[30] Rotter, J. M., Usmani, A. S.: Thermal Effects. In Proceedings of the First International Workshop "Structures in Fire". Copenhagen, $19^{\text {th }}$ and $20^{\text {th }}$ June 2000.

[31] Harada, Kazunori: Actual State of the Codes on Fire Design in Japan. In: fib Task Group 4.3 - Fire Design of Concrete Structures: What now? What next? Milano, 2004.

[32] Bailey, C. G., Toh, W. S.: Experimental Behaviour of Concrete Floor Slabs at Ambient and Elevated Temperatures. In Proceedings Fourth International Workshop "Structures in Fire". Aveiro, 2006.

Ulrich Schneider

e-mail: ulrich.schneider+e206@tuwien.ac.at

Martin Schneider b,

e-mail: e0527948@student.tuwien.ac.at

University of Technology Vienna

Karlsplatz 13/206

1040 Wien, Austria

Jean-Marc Franssen

e-mail: jm.franssen@ulg.ac.be

University of Liège

1, Ch. des Chevreuils, 4000, Liège, Belgium 


\title{
A New Design Method for Industrial Portal Frames in Fire
}

\author{
Y. Song, Z. Huang, I. Burgess, R. Plank \\ Industrial portal frames near to other buildings must keep their vertical walls standing in fire in order to prevent fire spread. A recently de- \\ veloped analysis, implemented in the program Vulcan, using a combination of static and dynamic solvers, has shown that the strong base \\ connections recommended by the current design method may not always lead to conservative design. A second-phase failure mechanism ob- \\ served in numerical modelling, and the critical temperature at which final run-away collapse occurs, may be higher than the temperature at \\ which the roof frame initially loses its stability, because a re-stabilisation often happens. A new method for estimating critical temperatures of \\ portal frames in fire, using these two failure mechanisms, is presented. Numerical tests on typical industrial frames are used to calibrate this \\ new method.
}

Keywords: Steel structures, portal frames, fire, boundary conditions, dynamic analysis, plastic theory, base connections.

\section{Introduction}

For single-storey steel portal frames in fire, especially when situated close to a site perimeter, it is imperative that the boundary walls stay close to vertical, so that fires which occur are not allowed to spread to adjacent properties. A current UK fire design guide [1] requires either that the whole frame be protected as a single element, or that the rafter can be left unprotected but the column bases and foundations should be designed to resist the forces and moments necessary to prevent collapse of the rafter, in order to ensure the lateral stability of the boundary walls. Some arbitrary assumptions regarding the behaviour of the frame in fire, which are used to simplify this current design model, can lead to very uneconomical foundation design and base-plate detailing. Further understanding of the behaviour of portal frames in fire is required, to provide other design options so that over-design of column bases and foundations can be avoided, and a more reasonable prediction of real critical temperatures can be made.

On the basis of fire tests, a simplified method to estimate the critical temperatures of portal frames in fire was developed by Wong in 2001 [2] for single-span portal frames with simple base connections. It was shown by numerical modelling that this method could predict the temperature at which the rafters initially lose stability in fire. A recently developed quasi-static analysis [3], implemented in the program Vulcan, using a combination of static and dynamic solvers, has also shown that the strong base connections recommended by the current design method may not always lead to a conservative design. A second-phase failure mechanism observed in numerical modelling corresponds with the failure mode shown in one of the previous fire tests. The critical temperature at which runaway collapse occurs may be higher than that at which the roof initially loses its stability, because of re-stabilisation.

In this paper, a new method is presented for estimating critical temperatures of single-span frames in fire, using these two failure mechanisms. Numerical tests on typical industrial frames are used to calibrate this new method against the current design method.

\section{Behaviour of single-storey portal frames in fire}

As early as 1979 the behaviour of steel portal frames in accidental fires was described in the report of a study [4] of fires in a number of portal frames in the UK. A typical variation of the overturning moment at the column base with time, after a fire is ignited in a pitched-roof portal frame is described in the CONSTRADO design guide [5]. It was believed that the stability of the column was mainly determined by the resistance provided by the column base connections. However, the fire test on a scaled pitched-roof portal frame performed in 1999 [2] showed that the steel columns, connected to their foundations by a fairly flexible connection, could stand almost upright throughout the fire while the rafters snapped through to a inverted shape. This indicates that strong column bases are not always essential to the stability of an industrial frame under fire conditions.

It has been postulated by O'Meagher et al. [6] that unaffected parts of a building can act as anchorage for the fire-affected zone, provided that the forces developed in the purlins are reasonably small and that they have sufficient capacity at high temperatures, so that cold frames will also deform in an acceptable mode. The results of a series of parametric studies [2] using two- and three-dimensional modelling showed that a portal frame with semi-rigid bases initially loses stability in a combined mechanism, which differs from the assumption used in the current design method. Further deformation could not be simulated because of the limitations of the static solver.

In a previous paper the behaviour of single-span pitched portal frames was simulated using the recently-developed quasi-static solver [3] in Vulcan. This showed that collapse of the frame happens in two phases [7]. It was also found that the initial collapse of the rafter is always caused by a plastic hinge mechanism which is based on the frame initial configuration. If the frame can re-stabilize when the roof is substantially inverted, a second plastic mechanism based on the re-stabilized configuration leads to eventual failure of the whole frame. 


\section{New design method}

A single-span portal frame fails either in the first-phase mechanism when it initially loses stability, or may re-stabilise for a while before collapsing in the second-phase mechanism. The simple method developed by Wong [2] is based on the initial configuration of the frame. Hence, it is capable of explaining the reason why frames initially lose stability in fire, but is not valid for frame collapse in the second mechanism, in which the deformation of the frame is significant. The estimation of the critical temperatures for a two-phase failure mechanism should be based on different initial configurations for each of the two phases.

\subsection{Estimation of first-phase failure}

When the roof of the frame starts to deform downward under the loading and fire temperature, the columns are pushed outward due to the change of geometry and to thermal expansion of the rafters. For a portal frame with frictionless pinned base connections, high rotations can be generated at these bases, caused by either elastic or plastic deformation. These rotations, together with the fire hinges formed at the apex and eaves, can generate a ombined plastic mechanism. Wong simple model, as shown in Fig. 1, uses this mechanism, whose kinematics is referred to the initial configuration of the portal frame. This method can only apply to the frame initial loss of stability at relatively low deflections. According to plastic theory, for the mechanism shown in Fig. 1, the fire hinge moments at corners 1 and 2 can be calculated. The ratio of the fire hinge moment to the normal moment capacity is given by the strength reduction factor at the critical temperature, so the critical temperature of this frame can be interpolated from stress-strain curves defined in Eurocode 3 Part 1. 2 [8].

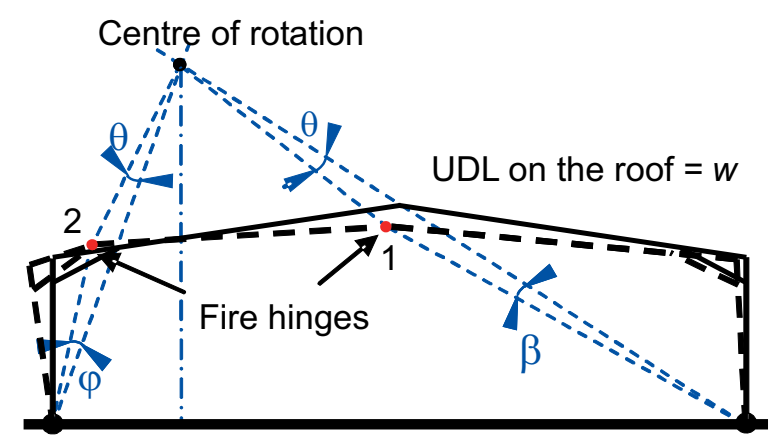

Fig. 1: The model of Wong's simple design method

\subsection{Estimation of second-phase failure}

The initial collapse of the roof frame may initiate a "combined" mechanism leading to collapse of the whole frame, or the columns may be pulled back towards the upright position (see shape $A B C D E$ in Fig. 2) due to the collapse of the rafters.

In the latter case the change of direction of the column's rotation causes elastic unloading of the base moments of the columns, so that the plastic hinges developed at the bases are effectively locked. When the pitched roof deflects further than the position $B C D$, column $A B$ is pulled inward, so that

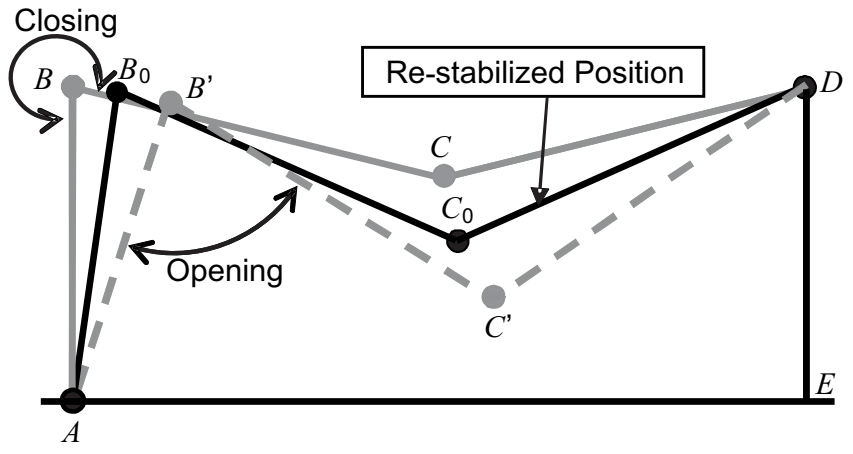

Fig. 2: Illustration of the second phase mechanism

the base moments of the columns increase again. When the rotation of column $A B$ is faster than the rotation of the adjacent rafter, the moment on one eave (corner $B$ ) starts to reverse, leading to locking of the adjacent plastic hinge. This causes the frame to re-stabilise at this position (shape $A B_{0} C_{0} D E$ in Fig. 2), at which the internal angle $\left(A B_{0} C_{0}\right)$ between column $A B_{0}$ and the connected rafter $B C_{0}$ stops closing and starts opening. With further increase of the pulling force at the column top caused by catenary action of the inverted roof, the fire hinges at the eave and column base can be mobilised again (shape $A B^{\prime} C^{\prime} D E$ in Fig. 2), and a new mechanism, referred to as the second-phase failure mechanism, is established which leads to complete collapse of the frame.

The new design method developed here focuses mainly on collapse caused by the second-phase mechanism in fire, and aims to predict the critical temperatures which initiate formation of the second-phase failure mechanism. The method is based on calculating the strength reduction factor of the fire hinge moment according to the work balance within the frame.

Because of the significant deformation of the roof frame before the start of the second failure mechanism, this new model has to identify the re-stabilised position of the frame and its critical position at the start point of the second-phase mechanism. Both the thermal elongation of rafters and degradation of fire hinge moments at elevated temperatures are considered under some temperature assumption. Moreover, because a plastic hinge at one column base is essential to generate a second-phase mechanism, the strength of the column bases is also included in this new method.

When the second-phase mechanism of the frame is established, the elongation of the rafters is significant. This should not be ignored when the work balance is calculated within this system. Estimation of the critical temperature for the second-phase mechanism of the frame is also based on the reduced moment capacity of the rafters. Because the strength reduction factor and the steel elongation at the critical temperature are both unknown, an iterative solution procedure, illustrated by the flow chart in Fig. 3, is required.

At the beginning of the second-phase calculation, an initial temperature $T_{0}$ is assumed, so the re-stabilised position can be estimated on the basis of the geometry of the frame, including the elongation of the rafter, at temperature $T_{0}$. The fire hinge moment can also be calculated on the basis of the configuration of the frame at the re-stabilised position (as 


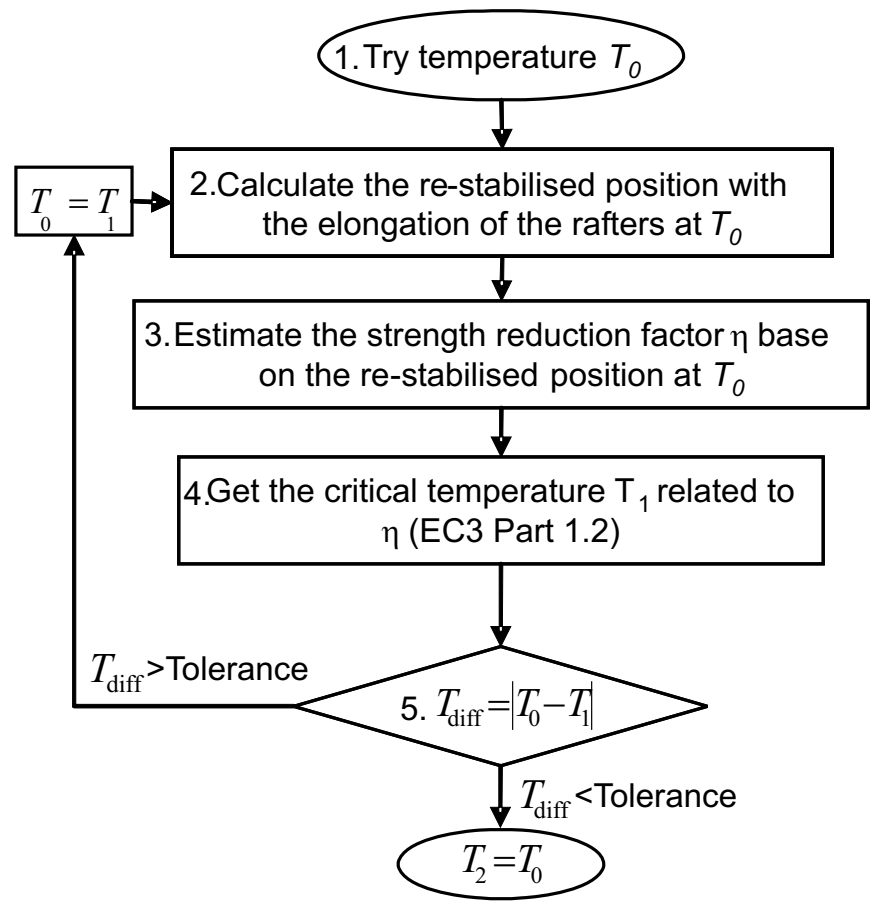

Fig. 3: The procedure for estimating the critical temperature of second phase failure

shown in Fig. 4) and the work balance based on plastic theory. The critical temperature $T_{1}$ can be obtained from the strength reduction factor given by dividing the fire hinge moment by the moment capacity of the rafter section, and relating this to the corresponding temperature, as defined in Eurocode 3 Part 1.2 [8]. If the difference between $T_{0}$ and $T_{1}$ is larger than the tolerance required, Steps 2 to 5 as defined in Fig. 3 are repeated, using the elongated lengths of the rafters at $T_{1}$, until $T_{\text {diff }}$ is smaller than the tolerance required. The temperature $T_{1}$ estimated from the final iteration is the critical temperature of the frame at the beginning of the second-phase mechanism.

\section{Validations against numerical tests}

In order to validate the new design method a series of comparisons has been conducted between critical failure temperatures predicted using the new design method and those obtained from previous numerical tests [9]. Because the two-phase mechanisms are included in this method, critical temperatures for the creation of both the first- and the second-phase mechanisms are compared.

Figs. 5 and 6 compare the critical temperatures predicted by the new design method and numerical analysis results for

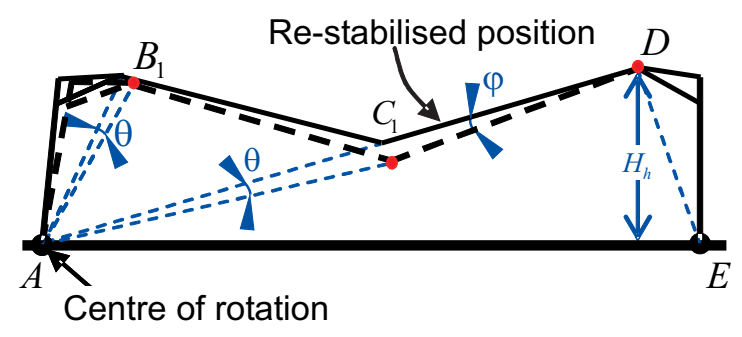

Fig. 4: Model of the second-phase failure two typical portal frames. The results presented in Fig. 5 are for the portal frame designed without haunches but with varying base strength. Results for the other portal frame, which is designed with typical-sized haunches and modelled with different base strengths, are shown in Fig. 6 .

The first re-stabilised position of the frame is reached when the rafter is deformed into the inverted position and the

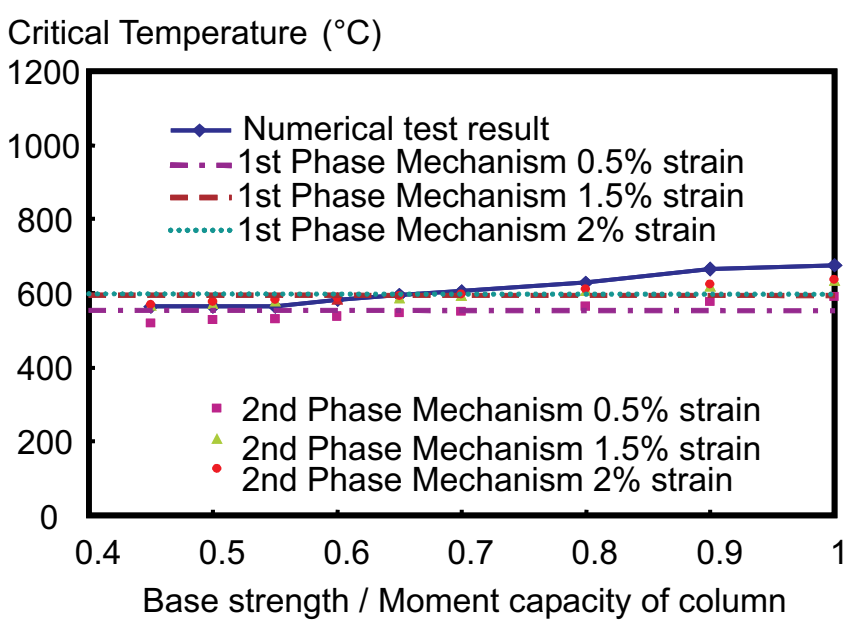

Fig. 5: Portal frames without haunches

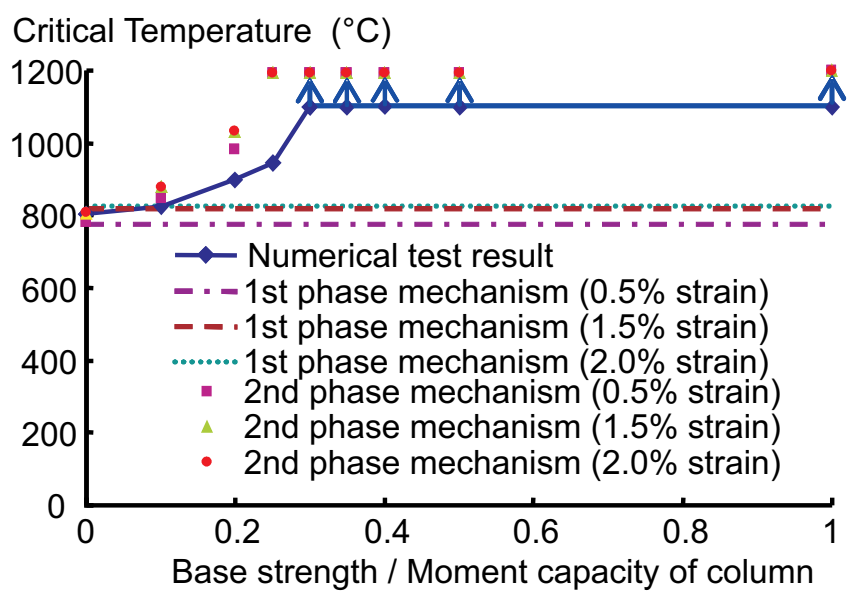

Fig. 6: Portal frames with haunches

vertical displacement of the apex is around $5 \mathrm{~m}$. The prediction of the new design method is $5 \mathrm{~m}$. This confirms that re-stabilisation during the collapse of the portal frame is caused by locking of the plastic hinge near to an eave, which disables the first-phase mechanism. Once the opening of the locked angle exceeds the elastic rotation limit, the frame loses its stability again.

For the frame with haunches, the re-stabilised position predicted by the new design method is about $0.4 \mathrm{~m}$ lower than for the numerical results. This is because, in the new design method, a re-stabilised position is assumed to occur when, in the first-phase mechanism, the rafter ceases to rotate relative to the column at hinge $B$ (Fig. 4 ) and this hinge consequently locks itself. When the hinge finally begins to rotate again, in the opposite sense to its original rotation, the second-phase mechanism is created and failure occurs. Locking of the plastic hinges developed at one of the column bases could also be encountered when the column is pulled inward and passes 
its original position, so collapse is arrested until the plastic hinge at the base A is unlocked. When this hinge is mobilised, the frame is capable of continuing to collapse until the fire hinge near the end of the haunch locks itself. This explains the difference between the re-stabilised positions predicted by numerical tests and this new design method. It is worth noting that the main purpose for estimating the re-stabilised position is to determine the critical configuration of the frame on the basis of the principle of work balance. Therefore the final equilibrium position of the frame before it collapses again should be adopted in order to estimate the critical temperature.

From the previous numerical studies, the portal frame would fail in its first-phase mechanism when the ratio between the base strength and moment capacity of the column is lower than 0.55 for the unhaunched case and 0.1 for the haunched case. The reduced "yield stress" at $0.5 \%$ steel strain leads to a better prediction of the critical temperature of the frame without haunches in the new design method. As shown in Fig. 5 the critical temperatures predicted by the new method for the second-phase mechanism according to the strength reduction factors at $1.5 \%$ and $2.0 \%$ strain show a similar trend to the numerical results.

From Fig. 6 it is evident that, for a haunched frame with base strength equal to $10 \%$ of the moment capacity of the column section, the critical temperatures predicted by the new design method for the first-phase mechanism are very close to the numerical results. However, the numerical analyses give higher limiting temperatures for cases with base strength greater than $20 \%$ of the moment capacity of the column.

In the new design method, the strength reduction factor obtained from equilibrium on the basis of the second-phase mechanism becomes negative when the base strength is higher than $30 \%$ of the moment capacity of the column. This means that the work done by the plastic hinges developed at the bases exceeds the work done by the external forces, and hence the second-phase mechanism cannot happen, and the frame will stand in its re-stabilised position under further temperature increases.

\section{Conclusion}

A new design method, extended from Wong's model is presented in this paper. In this method, instead of relying on a single failure mechanism, the two most common failure mechanisms for pitched portal frames under fire conditions are considered to predict the critical temperatures of the frame. The critical temperatures predicted by the new design method on the basis of the first-phase failure mechanism show very good agreement with the numerical results at which a typical frame initially loses stability in fire. Very reasonable predictions about the re-stabilised position and the final collapse temperatures of the frames were achieved using this new design method. It is evident from this study that the initial collapse of the frame due to the first failure mechanism is often a temporary instability, and that after this the frame can experience a second-phase mechanism with a higher critical temperature, which depends on the base strength and the loading conditions of the frame.

When the frame collapses at the beginning of the first-phase mechanism, the inclination of the columns may be relatively small, so this could be a lower bound for the design of portal frames in a fire boundary condition. The re-stabilisation after the initial loss of stability of the frame can be estimated from the critical temperature predicted on the basis of the second-phase mechanism. In this new design method, when the strength reduction factor, calculated from work equilibrium for the second-phase mechanism of the frame, becomes negative it is possible that the portal frame could remain in its re-stabilised state after snap-through of the pitched roof, and may not collapse until a very high temperature is reached.

\section{References}

[1] Simms, W. I., Newman, G. M.: SCI Publication P313: Single Storey Steel Framed Buildings in Fire Boundary Conditions (2002 edn.). The Steel Construction Institute, 2002.

[2] Wong, S. Y.: The Structural Response of Industrial Portal Frame Structures in Fire, PhD Thesis, University of Sheffield, 2001.

[3] Song, Y., Huang, Z., Burgess, I. W., Plank, R. J.: The Behaviour of Single-Storey Industrial Steel Frames in Fire. Acc. Advanced Steel Construction: an International Journal, 2008.

[4] CONSTRADO: The Study of the Behaviour of Portal Frames in Fire when Subject to Boundary Conditions. The Constructional Steel Research and Development Organisation, 1979.

[5] CONSTRADO: Fire and Steel Construction: The Behaviour of Steel Portal Frames in Boundary Conditions. The Constructional Steel Research and Development Organisation, 1980.

[6] O'Meagher, A. J., Bennetts I. D., Daywansa, P. H., Thomas, I. R. and BHP Research, Melbourne Laboratories: Design of Single Storey Industrial Buildings for Fire Resistance. Journal of Australian Institute of Steel Construction, Vol. 26 (1992), No. 2.

[7] Song, Y., Huang, Z., Burgess, I. W., Plank, R. J.: A New Design Method for Industrial Portal Frames in Fire, Proc. Structures in Fire Workshop, 2008, p. 302-312.

[8] CEN, BS EN 1993-1-8:2005: Eurocode 3: Design of Steel Structures: Part 1.2: General Rules-Structural Fire Design, European Committee for Standardization, 2005.

[9] Song, Y.: Analysis of Industrial Steel Portal Frames under Fire Conditions. PhD Thesis, University of Sheffield, 2009.

Yuanyuan Song

Safe Consulting Limited

Manchester, UK

\section{Zhaohui Huang}

Ian Burgess

e-mail: ian.burgess@sheffield.ac.uk

Department of Civil and Structural Engineering

Roger Plank

School of Architectural Studies

The University of Sheffield

Western Bank

Sheffield S10 2TN, UK 